\title{
FOUNDATION PRECOMPRESSION WITH VERTICAL SAND DRAINS \\ by
}

S. J. Johnson

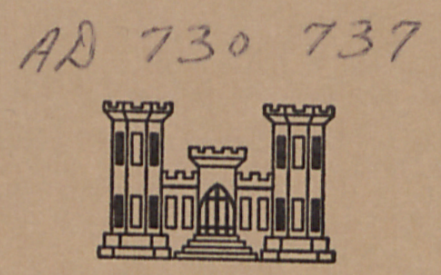

June 1969 \section{CORPS OF ENGINEERS}

Vicksburg, Mississippi

THIS DOCUMENT HAS BEEN APPROVED FOR PUBLIC RELEASE AND SALE; ITS DISTRIBUTION IS UNLIMITED 


\section{FOUNDATION PRECOMPRESSION WITH VERTICAL SAND DRAINS}

by

S. J. Johnson

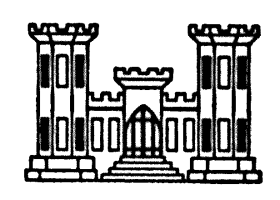

June 1969

Published by

U. S. Army Engineer Waterways Experiment Station CORPS OF ENGINEERS

Vicksburg, Mississippi

ARMY.MRC VICKSEURG. MISS.

THIS DOCUMENT HAS BEEN APPROVED FOR PUBLIC RELEASE AND SALE; ITS DISTRIBUTION IS UNLIMITED 


\section{Foreword}

This state-of-the-art paper was presented by Mr. S. J. Johnson at the American Society of Civil Engineers Specialty Conference on Placement and Improvement of Soils to Support Structures, which was held at.the Massachusetts Institute of Technology in August 1968, and will be published in the Proceedings of the Conference. The paper was cleared for presentation and publication by the Office, Chief of Engineers (ENGTL).

Mr. Johnson is Special Assistant in the Soils Division, U. S. Army Engineer Waterways Experiment Station (WES).

The Director of WES during the preparation of this paper was COL Levi A. Brown. Technical Directors were Messrs. J. B. Tiffany and F. R. Brown. 
FOUNDATION PRECOMPRESSION WITH VERTICAL SAND DRAINS

By Stanley J. Johnson, * F. ASCE

\section{INTRODUCTION}

The use of preload fills and other means to precompress, soils in advance of construction of permanent facilities is a relatively inexpensive but effective method for improving poor foundation soils. The benefits of precompression are to increase shear strength and to decrease postconstruction settlements to tolerable values. Temporary surcharge loading does not accelerate the rate of consolidation; instead, it achieves essentially the same degree of consolidation under a higher load, which represents, in effect, a higher degree of consolidation under the reduced load remaining when the surcharge load is removed. Temporary surcharge loading makes it possible to eliminate, in advance of construction of structures or paving of roadways or runways, subsoil settlement that would otherwise occur subsequent to completion of construction. The amount of settlement that is generally eliminated is 100 percent of primary consolidation plus such amount of secondary compression as is required to reduce postconstruction secondary compression settlements to tolerable values.

Precompression through use of surcharge loads only ${ }^{I}$ is economical and simple; however, many compressible subsoil deposits are sufficiently thick or impermeable so that consolfdation occurs slowiy, and preload fills required to precompress

Special Assistant, Soils Division, U. S. Army Engineer Waterways Experiment - Station, Vicksburg, Mississippi. 
the soil within the time available may become so high that they become uneconomical or, because of possible foundation instability, require large and costly berms. When this happens, it may be attractive to install artificial internal drainage channels in the poor subsoils to accelerate the rate of consolidation.

Permeable sand or silt layers often are found within the poor soil so that additional drainage paths are not required. Unfortunately, these natural and highly effective drainage layers are often overlooked when they are thin, especially when continuously sampled borings are not made. However, even if continuous sand or silt layers are found, they may be so thin or have such a low permeability that head losses in them become excessive if the drainage path 1s long. Further, it may be difficult, during the design stage, to predict their effectiveness with reasonable effort. Where the effectiveness of intermediate sand or silt layers is in doubt or when such layers do not exist, positive means for accelerating drainage may be desirable. One means for doing this consists of installing vertical sand drains. Since vertical sand drains cost money, they obviously should be installed only where subsoil studies show them to be required and cost studies have established their superiority over other construction alternatives. The use of vertical sand drains is, in effect, a detail incidental to use of the precompression technique for improving properties of compressible subsoils, and factors involved in precompression ${ }^{1}$ apply also where sand drains are used. 


\section{FUNCTIONS OF VERTICAI SAND DRAINS}

Vertical sand drains consist of a cylindrical column of free-draining granular soil placed in a vertical hole created in a compressible soil formation. The drains are generally connected at original ground surface with a drainage blanket. The benefits of sand drains, regardless of the purpose for which they are installed, result solely from increasing the rate of consolidation. When relatively impervious compressible soil is loaded, water in the soil voids is put under pressure. that slowly decreases with time as drainage occurs. Vertical sand drains merely provide additional drainage channels to facilitate escape of pore water, thereby accelerating consolidation. It is obvious, although sometimes overlooked, that loads must be superposed on the soil to cause the desired consolidation and drainage of pore water. A section through a typical sand drain preload project is shown in Fig. 1. 


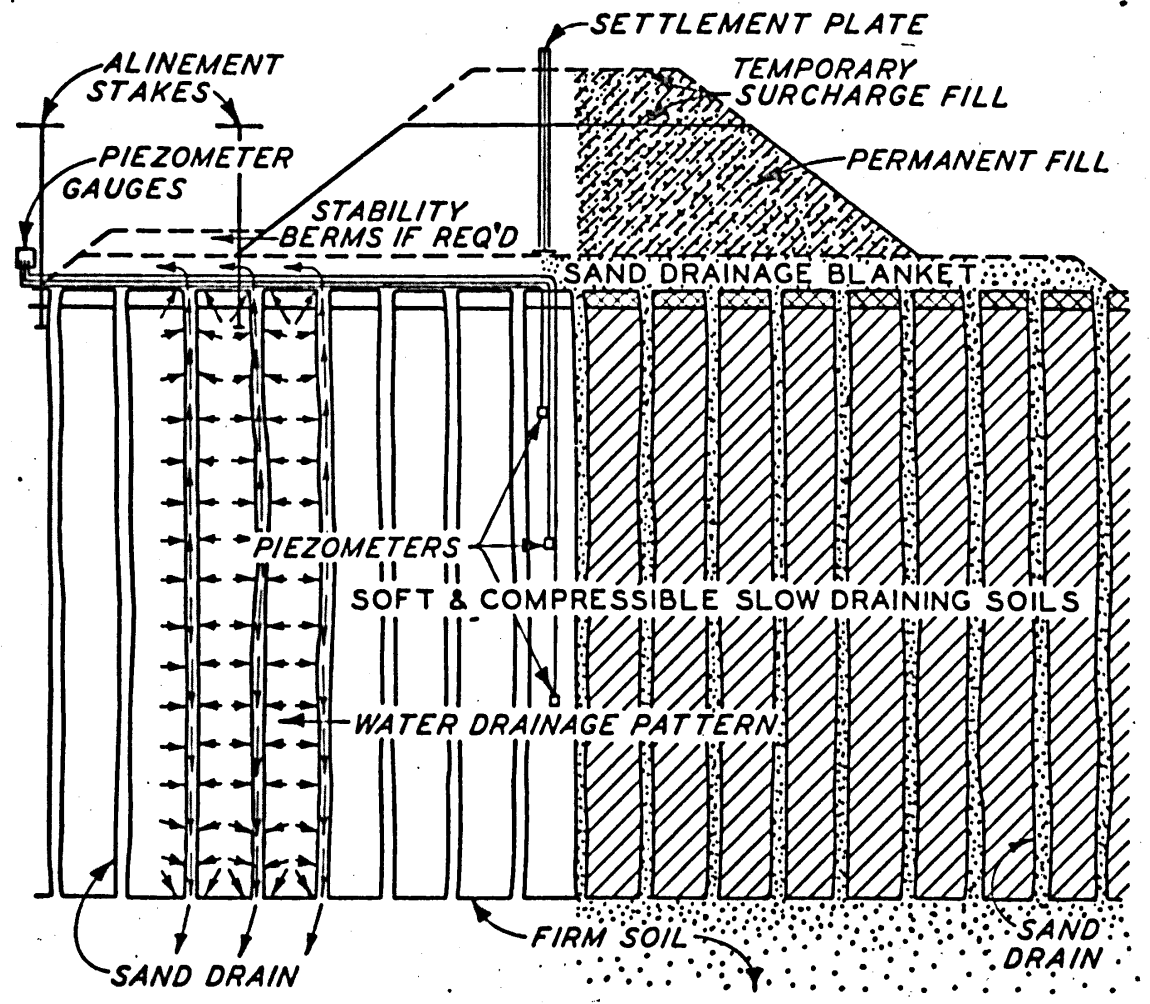

TYPICAL SAND DRAIN INSTALLATION 


\section{HISTORICAI DEVELOPMENT OF VERTICAI SAND DRAINS}

Vertical sand drains were first proposed by Daniel E. Moran in 1925 as a means for deep soil stabilization, and he received a patent on this process in 1926. The first application was proposed by Moran as a means for stabilizIng the mud foundation beneath the easterly roadway approach to the San Francisco-Oakland Bay Bridge. This led to laboratory and field experiments by the California Division of Highways in 1933 and 1934 and to installation of the first sand drain system in 1934. These trials were successful and led to further use and development, first by the California Division of Highways as a result of the interest of 0 . J. Porter, ${ }^{2}$ then in the eastern United States by the Corps of Engineers ${ }^{3}$ beginning in 1941, and about the same time by Terzaghi. ${ }^{4,5}$ Since that time the variety of projects to which sand drains. have been applied has been constantly increasing.

Theoretical design procedures were not avallable when sand drains were first used, and early installations were designed on an empirical basis. Design procedures based on Terzaghi's theory of consolidation of compressible soils were developed by R. A. Barron ${ }^{3,6}$ in the period 1940 to 1942. Prior to his work, others had worked on the problem including Rendulic ${ }^{7}$ and Carrillo, ${ }^{8}$ but Barron's was the most extensive. His work is the basis for practically all sand drain design which considers consolidation by radial and vertical flow. As part of a review 9,10 of the use of vertical sand drains, sponsored by the Bureau of Yards and Docks, Richart ${ }^{10,11}$ introduced the use of numerical: procedures.

While the design of vertical sand drain.systems evolved quite early from an empirical process to one based on theoretical considerations, the relation of soil properties to design procedures and the variability of "soil constants" 
were not emphasized until about 1958, when the review of sand drain use was made by Moran et al. ${ }^{10}$ This review, commonly referred to as the Sand Drain Report, presented precompression design procedures, including partial elimination of secondary compression settlements, and reviewed numerous case histories where sand drains had been used. It was found that slides often occurred during construction, although sand drains achieved beneficial results in many cases. The Sand Drain Report concluded, in effect, that problems with sand drains and associated preloads resulted primarily because of misconceptions regarding stability and consolidation analyses or because of uncontrolled field operations rather than because of limitations of the concept. Many engineers using sand drains formerly assumed that their use automatically would ensure foundation stability, whereas essentially the same type of foundation stability problems exist with or without sand drains. Similarly, detailed consolidation analyses are required where sand drains are used; they cannot be used on purely an empirical basis.

The historical development of sand drains starts out with a crude beginning followed by continuous development as it became obvious that more careful design and construction supervision were required. Despite the major cost savings associated with use of sand drains and preloading, and the numerous difficulties that have occurred, remarkably little research has been done on their use. Fortunately, this seems to be changing, but still only a few significant field investigations have been made of the performance of sand drains and of differences between the various types of drains. 
When planning and scheduling work in areas where the precompression technique may be applicable, with or without vertical sand drains, the factor that must forever be borne in mine is that stabilization through consolidation requires time. It is simply impossible to load a fine-grained, slow-draining soil and expect it to consolidate rapidly, either with or without sand drains. In some cases, highly compressible soils are relatively permeable and may consolidate in a few monțhs. On the other hand, even with a high surcharge fill and with sand drains, the time required may be a year or even more. Because economic benefits resulting from precompression can be achieved only if the necessary time is available, those responsible for planning construction work in areas having poor subsoils must anticipate the additional time required for detailed soil investigations and for consolidation under reasonable surcharge loadings. The most important decisions affecting foundation design in areas having poor subsoils may be made, in effect, by those planning the work.

Probably no single tool or technique employed by the soils and foundations engineer is as powerful as the use of surcharge fills with or without sand drains, from the standpoint of a high rate of return on invested effort. These techniques have saved many millions of dollars where properly used, but time is often the most important factor affecting results. Precompression, with vertical sand drains, is especially suitable for large loaded or filled areas not having heavy concentrated loads. It is not applicable or economical for all conditions, but where properly used, can reduce postconstruction settlements to tolerable values. The method requires especially careful design studies and field supervision. 
The precompression technique with vertical sand drains has been used on a wide variety of applications, ${ }^{1,10,12}$ as listed in Table 1; but whatever the application, the basic purpose is generally to increase stability, to decrease postconstruction settlement, or both.

The relative cost of highway structure versus the precompression technique using earth fills with surcharge, with and without sand drains, is shown in Fig. 2, after Landau, ${ }^{13}$ and illustrates how major cost savings are sometimes possible on highway projects. Weber ${ }^{14}$ cited one case where precompression with sand drains cost $\$ 120,000$ less per station than a structure. Since some swamps involve a few miles to 10 or 20 miles of roadway, potential savings can be large. Equally impressive savings are sometimes possible where structures are to be constructed.

Vertical sand drains extend the range of applicability of the precompression technique and make its use possible where compressible subsoils are thick or their permeability very low. Considerations applying to precompression without sand drains ${ }^{l}$ apply also where sand.drains are used, although some modifications in design practices to account for the radial flow toward the drains are required. While properly designed and supervised precompression applications with vertical sand drains are considered reliable, their improper use has resulted in numerous and costly failures, involving not only the work itself but also adjacent structures. However, this comment can be made for almost any construction operation. 


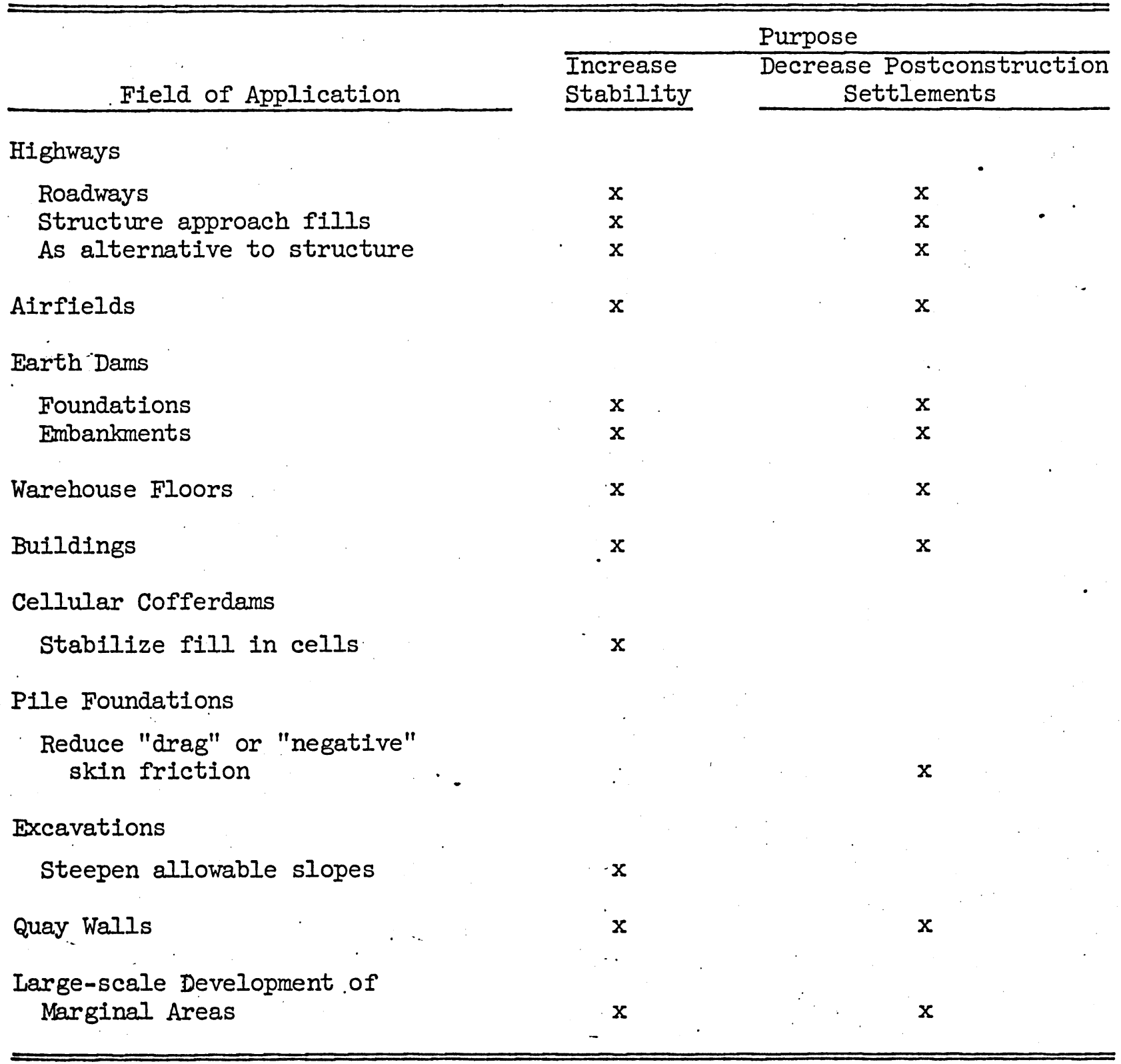




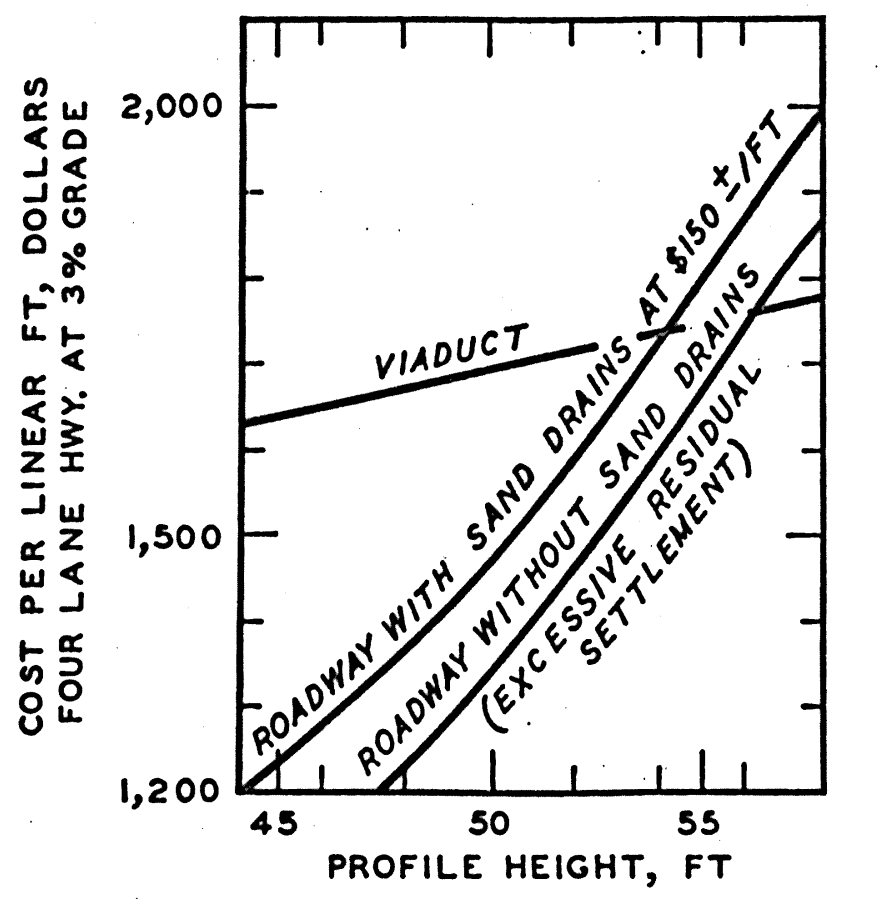

COST OF STRUCTURE

VS EARTH FILL

FOR HWY. CONST.

(AF TER LANDAU) 
It is virtually impossible to emphasize adequately the importance of the geology of an area and the detailed subsoil characteristics of a site. A detailed subsoil investigation and study that produce continuous samples of the highest quality obtainable are required so that subsoil stratification, strength, and consolidation characteristics can be determined and good estimated preconsolidation stresses obtained. While this requires considerable time and is relatively expensive, satisfactory feasibility designs for comparative cost studies are generally possible using correlations ${ }^{l}$ and relatively incomplete subsoil Information. If the method is applicable, the added cost of the more detailed subsoil investigations and design studies required for proper use of the precompression technique, with or without sand drains, is a minor fraction of cost savings.

If a soil is sufficiently preconsolidated, there may be no need to consider sand drains because settlements will be small and occur rapidly. ${ }^{l}$ However, if a fine-grained soil is normally consolidated or only slightly preconsolidated with respect to design loadings, it may consolidate slowly, and sand drains may be required. Most peaty soils are so pervious that sand drains are not required; however, such soils are generally underlain by soft clays that consolidate slowly, and sand drains in them may be necessary. Also, the permeability of peatj soils may decrease to extremely low values where loadings are high. Sand drains affect only the rate of primary consolidation and have no direct influence on secondary compression settlements. Subsoil characteristics and conditions affecting precompression design without sand drains ${ }^{1}$ also apply where sand drains are used. 
THEORY OF CONSOLIDATION FOR SAND DRAIN DESIGN

The theory of consolidation for design of vertical sand drains considers combined radial and vertical pore-water flow to the drains (see Fig.3) and has been developed in detail by Barron as an extension of Terzaghi's basic work. Combined vertical and radial flow to sand drains can be treated analytically 6,8 as separate, vertical, and radial flow problems. The excess pore-water pressure ratios at any time for these separate types of drainage can be multiplied together to determine their combined effect (see Fig. 4). Vertical consolidation is analyzed in the usual manner using the Terzaghi consolidation theory (see Fig. 5 for design chart): or later refinements, if desired. Radial consolidation is analyzed in practically the same manner, using Barron's analyses and design charts, such as Figs. 6, 7, and 8. The differences between assuming equal vertical strain or uniform vertical stress, free strain was investigated by Barron 3,6 and found to be minor. The equations for equal vertical strain on a horizontal plane are simpler and are commonly used in design and for evaluating field piezometer and settlement observations.

The analyses by Barron include conditions in which the permeability of soil adjacent to the walls of the sand drain is reduced because of smear or disturbance occurring during installation of the drain, and convenient design charts for this case were developed by Richart as part of the sand drain review. 10,11 He also considered the effect of a variable void ratio. Hansbo ${ }^{15}$ modified Barron's analyses for the equal strain case for the condition in which drainage is proportional to a power of the hydraulic gradient and reported improved comparison with a field test installation when the gradient was raised to about the 1.5 power. Schiffman ${ }^{16}$ considered the effect of linear construction Ioading, and also of varying permeability, and Rowe ${ }^{17}$ applied solutions by Horne ${ }^{18}$ to consolidation of stratified soil by radial flow to sand drains. Younger ${ }^{19}$ has 


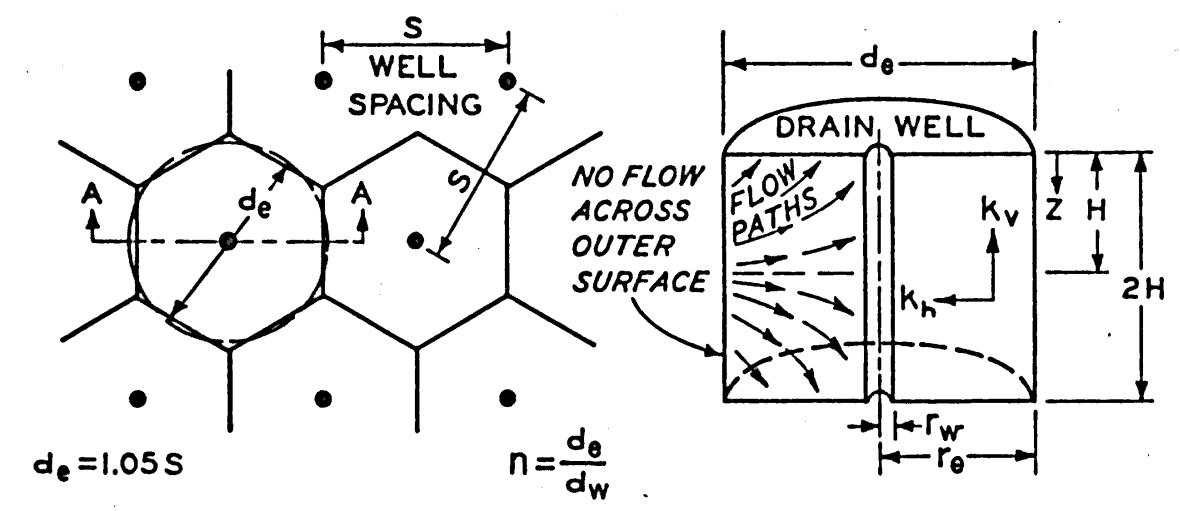

a. PLAN OF DRAIN WELL PATTERN b. SECTION A-A

FLOW TO VERTICAL SAND DRAINS 


\section{SUMMARY OF CONSOLIDATION THEORY FOR}

\section{SAND DRAIN DESIGN}

\section{VERTICAL CONSOLIDATION:}

$$
C_{v-v}=\frac{k_{v}\left(1+e_{0}\right)}{a_{v-v} \gamma_{w}}=\frac{H^{2} T_{v}}{t} ; \quad \text { OR } \quad t=\frac{T_{v} H^{2}}{C_{v-v}}
$$

\section{RADIAL CONSOLIDATION:}

$$
c_{v-h}=\frac{k_{h}\left(1+e_{0}\right)}{a_{v-v} \gamma_{w}}=\frac{d_{e}^{2} T_{h}}{t} ; \quad \text { OR } \quad t=\frac{T_{h} d_{e}^{2}}{C_{v-h}}
$$

\section{COMBINED RADIAL AND VERTICAL FLOW:}

AT ANY TIME:

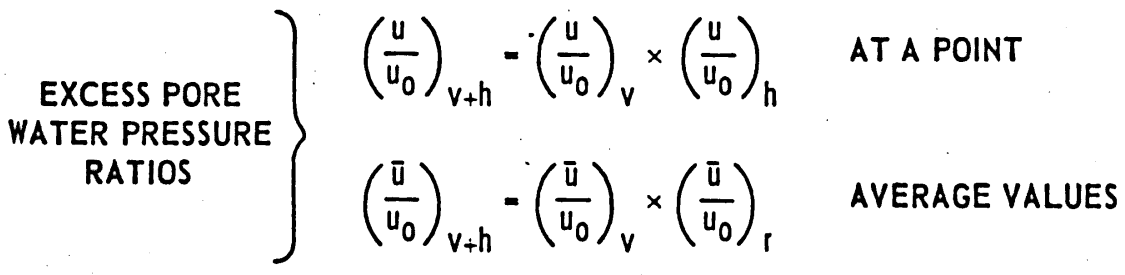

$$
\left.\begin{array}{c}
\text { DEGREE OF } \\
\text { CONSOLIDATION }
\end{array}\right\} \begin{array}{ll}
u=1-\frac{u}{u_{0}} & \text { AT A POINT } \\
\ddots \bar{U}=1-\frac{\bar{u}}{u_{0}} & \text { AVERAGE VALUE }
\end{array}
$$




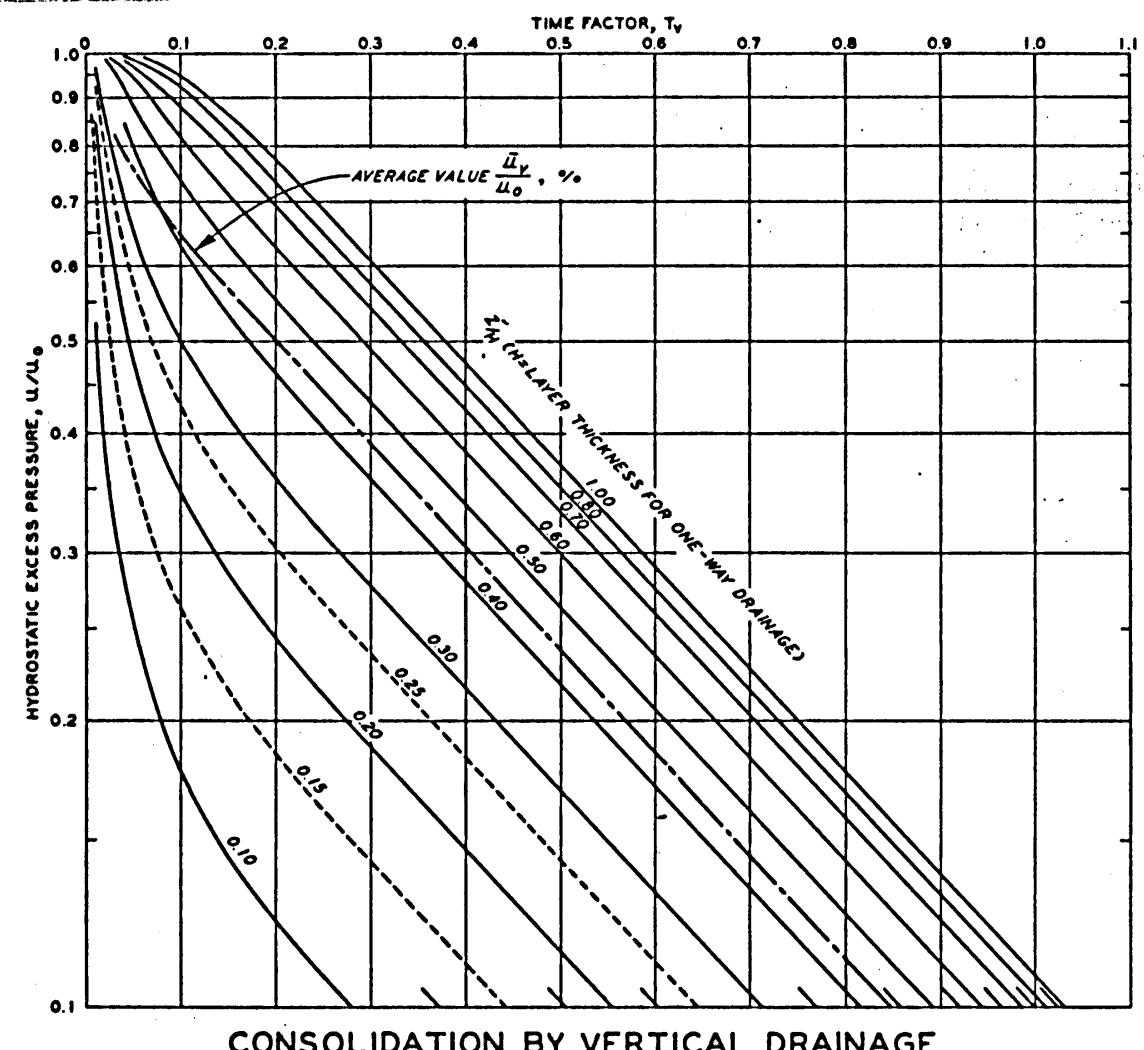

HYDROSTATIC EXCESS PRESSURE AS FUNCTION OF TIME FACTOR, TV, AND POSITION, $Z / H$, AND AVERAGE FOR ENTIRE LAYER, $\frac{\bar{\mu}}{\mu_{0}}$ 
COEF. OF.CONSOL. SUPP. DIAM OF TIME SUBS.
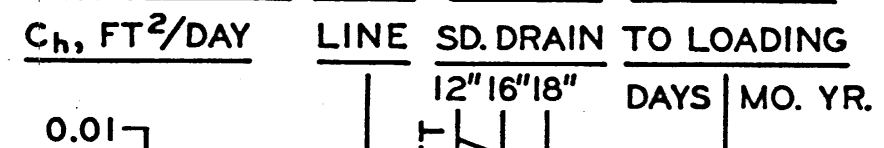

0.01

$0.02-$

0.04 (3)

$0.05-$

$0.06=$

0.07

$0.08-$

$0.10-$

.
$0.20-$
0.30
常
a

a
AVG. EXCESS PORE . AVG. CONSOL. WATER PRES. $\frac{u}{u_{0}}, \%$ 范 $\%$

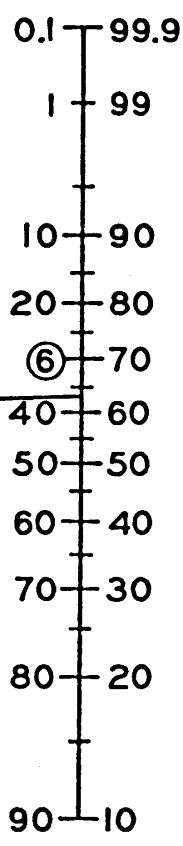

NOMOGRAPH FOR CONSOLIDATION WITH RADIAL DRAINAGE TO VERTICAL SAND DRAINS

EQUAL STRAIN CONDITION 


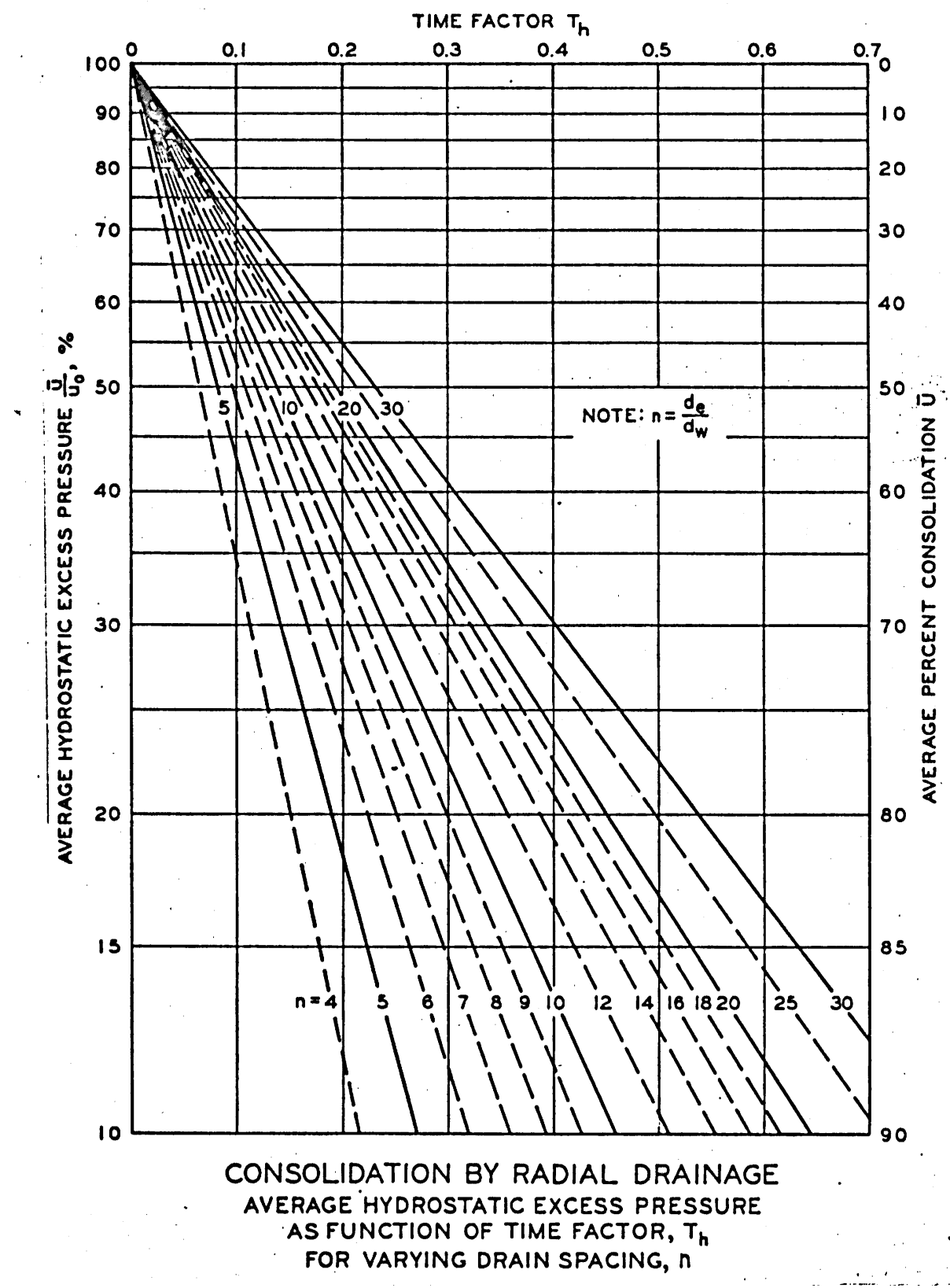




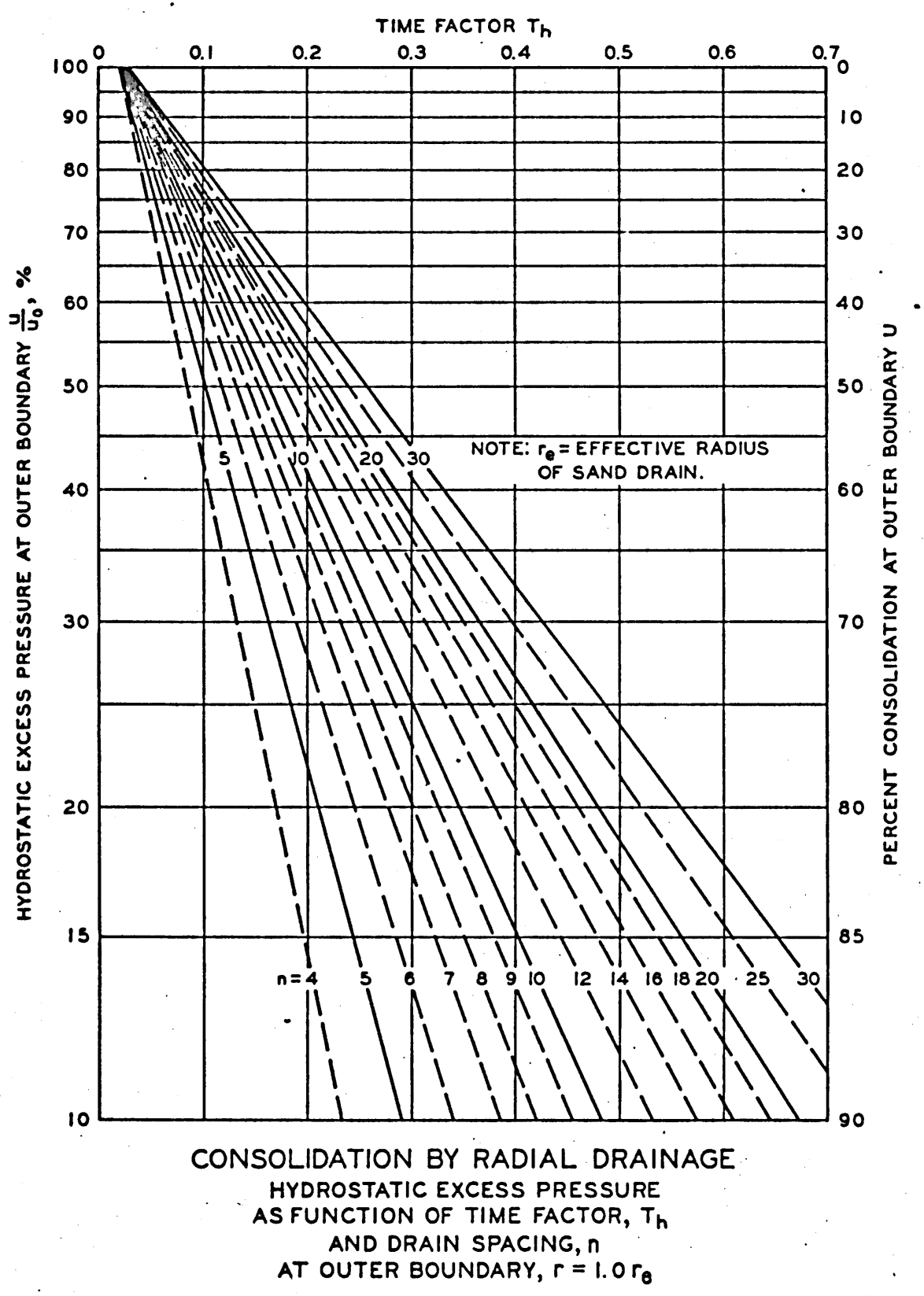


presented convenient design charts for combined radial and vertical flow. Available consolidation theories have many limitations and are essentially small strain theories, which are not strictly applicable for the large deformations that often occur where sand drains are used. However, much work is being done to overcome these deficiencies and to approximate more closely actual physical properties of soil, such as the variation of $c_{v}$ with time. However, even the newest available procedures do not consider both the space and time variation of $c_{v}$ that occurs during consolidation.

Because primary consolidation with sand drains occurs relatively rapidly and is completed during the preloading period, it is generally necessary to estimate secondary compression settlements occurring subsequent to completion of construction, and it may be necessary to increase the height of surcharge fill to compensate partially for settlements from this source. The techniques for doing this have been discussed at some length ${ }^{I}$ and apply generally without significant modification where vertical sand drains are used. 


\section{DESIGN CONSIDERATIONS}

\section{General Factors}

When considering subsoil precompression with possible use of sand drains to accelerate consolidation, two preliminary questions deserve special attention. The first question concerns the adequacy of boring information: more specifically, have sufficient continuously sampled borings been made to determine if intermediate drainage layers exist that might eliminate the need for sand drains? The second question concerns the adequacy of subsoil testing: specifically, are good estimates of preconsolidation stresses available? If the soil is normally consolidated, or preconsolidated but design loads substantially exceed preconsolidation stresses, use of the precompression technique may be practicable only if sand drains are provided to accelerate consolidation. However, if preconsolidation stresses exceed design loadings, consolidation will be rapid and sand drains almost certainly will not be required.

Another major factor is the time required for consolidation. If the client cannot accept the required consolidation time, the engineer should not optimistically assume that field times are less than predicted times; because while this is often true, the reverse is also often the case. Also, when considering the possibility of eliminating sand drains and using a surcharge fill only, which is more economical, the engineer must evaluate carefully if this type of risk is acceptable and worthwhile to the client; and, of utmost importance, is the client aware that it is he that must accept this type of risk? Sometimes it may be necessary to use sand drains as a safety factor. The rapid rate of construction commonly precludes a "design-as-you-go" approach, but a "confirm-as-you-go" approach is essential. Some clients with many precompression stabilization applications may willingly omit sand drains and rely only on surcharge loading, even. though occasionaliy more time may be required than 
expected, whereas this may not be appropriate for other clients.

Relatively trivial details generally determine if results from sand drain installations are satisfactory. These minor details confront the engineer at many steps in his analysis and subsequently during construction. Because of their importance, some of these details are discussed briefly. Coefficient of Consolidation

The coefficient of consolidation for radial flow and vertical compression dominates sand drain design and is principally dependent upon the horizontal permeability of a deposit and to a somewhat lesser extent, in the sense that It is less variable, upon the coefficient of compressibility. The coefficient of consolidation for radial drainage in uniform soil deposits can be determined from laboratory tests on undisturbed samples and will normally equal or exceed values obtained for laboratory consolidation tests with vertical drainage. It is becoming increasingly common to perform laboratory consolidation tests for sand drain design with special consolidometers to simulate radial flow to sand drains, as discussed by Rowe and Barden, ${ }^{20}$ Rowe and Shields, ${ }^{21}$ Shields and Rowe, ${ }^{22}$ Aboshi and Monden, 23 and Kulkarni et al. ${ }^{24}$ While the horizontal permeability of apparently uniform deposits is often larger than the value for vertical flow, this ratio cannot be assumed to be larger than one unless appropriate tests have been made, ${ }^{10}$ and some data ${ }^{25}$ show that the ratio of field to conventional laboratory values for vertical flow can be less than one for high moisture content materials.

Sedimentary deposits where the precompression technique with sand drains may be used are often stratified and should be explored by continuously sampled undisturbed borings to reveal even thin sand or silt layers. If these more permeable layers are continuous, they will greatly accelerate consolidation, but this may not occur where loaded areas are large ${ }^{l}$ uniess pressure relief 
wells or sand drains are provided to maintain their efficiency as drainage iayers. Design values for the coefficient of consolidation for radial flow to sand drains must reflect the effect of anisotropic permeability within the clay and, more importantly, the effect of any continuous sand or silt layers. While this can be done to a limited extent by performing laboratory consolidation tests on large samples, it is better to compute it using results from field. in-place permeability tests (Hvorslev ${ }^{26}$ ) and values of the coefficient of compressibility from conventional consolidation tests, as recommended by the sand drain review, ${ }^{10}$ by Cedergren and Weber, ${ }^{25}$ and by Weber. ${ }^{27}$ However, if the latter procedure is followed or if large samples are tested in the laboratory, it is necessary to reduce the field value of the coefficient of permeability for radial flow because of the lower void ratios and permeability that will develop as consolidation occurs during preloading, which may reduce field permeabilities by a quarter to a tenth of the initial value. ${ }^{25}$ Furthermore, the effects of soil disturbance resulting from sand drain installation may have to be considered when determining the coefficient of consolidation for radial flow from results of field permeability tests or from laboratory consolidation tests simulating radial drainage. This will be discussed subsequently.

Because the coefficient of consolidation generally decreases with consolidation, i.e., with increasing effective stress, and soil near the sand drain or other drainage faces consolidates rapidly (see Fig. 9), design values for the coefficient of consolidation for both vertical and radial drainage should correspond to about maximum, or only slightly lower, effective stresses induced by surcharge loading. The rapid consolidation near the edge of the sand drain probably has the effect of a "smeared" zone; regardless of the method of installing the sand drain.

The important influence of sand or silt layers, even though thin, on the overall value of the coefficient of consolidation for radial drainage to sand 


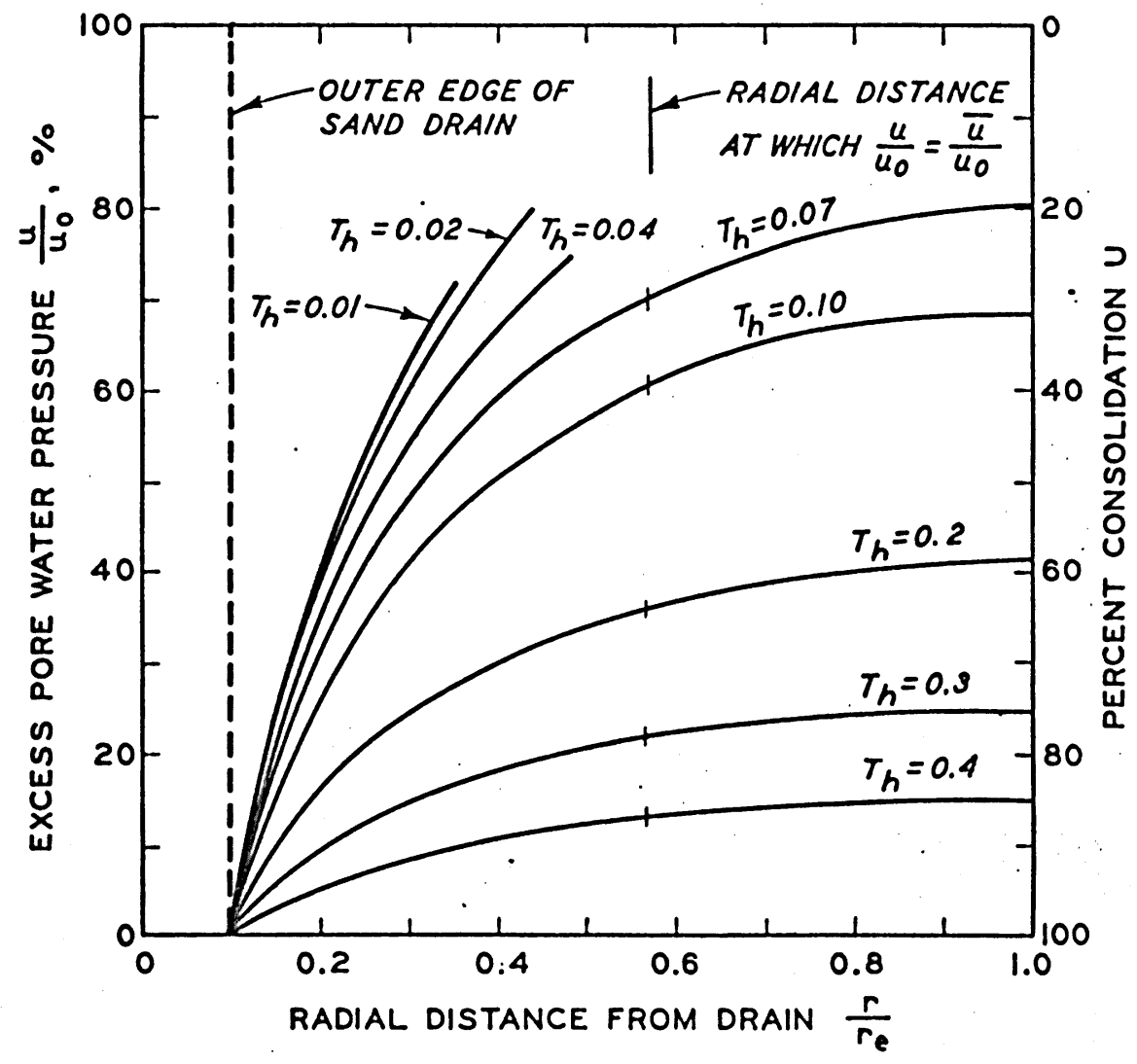

EXCESS PORE WATER VS

RADIAL DISTANCE FROM SAND DRAIN

RADIAL FLOW ONLY, $n=\frac{r_{e}}{r_{W}}=10$ 
drains has been discussed in much detail by Rowe, ${ }^{28}$ who recommends laboratory consolidation tests on specimens $10 \mathrm{in.} \mathrm{in} \mathrm{diameter} \mathrm{by} 5$ in. thick. The design and surcharge loadings relative to the preconsolidation stress must also be studied carefully, because of the high coefficients of consolidation generally found for stresses less than the preconsolidation stress. Where soils contain thin layers of sand or silt, the effect of these layers may be almost impossible to assess unless field loading tests are made over areas with and without sand drains.

Surcharge Design

While surcharge loadings designed for vertical consolidation without sand drains should generally be based on the degree of consolidation at the center of the compressible stratum. ${ }^{1 .}$ when using sand drains, it is considered satisfactory to determine required surcharge loading from the average degree of consolidation between sand drains instead of the value midway between drains. The procedure for determining required surcharge loading to achieve desired precompression in the specified time, as discussed for precompression without sand drains, ${ }^{I}$ is also directly applicable when using sand drains. ${ }^{10,12}$ The only change required in the procedure given in Reference $I$ is to use $U$ as $\bar{U}$, the average degree of consolidation, in Eq. 4 and in Fig. 15 of Reference 1. The time factors $T_{v}$ and $T_{h}$, shown in Figs. 5 and 7 , respectively, can be determined using average values of $\bar{u}_{0} \cdot$ Where final design loadings are relatively. uniform and cover a large area, as beneath embankments or uniformly loaded floors, the controlling design condition can be taken as the average degree of consolidation between sand drains on a plane along the center line of the compressible stratum. However, footings supporting concentrated building loads may cause the upper part of the compressible stratum to control the precompression design, and both conditions should be checked. 
Postconstruction settlements resulting from secondary compression should be evaluated using the same procedures as for precompression without sand drains. ${ }^{I}$ As for the latter case, it appears satisfactory to design on the premise that appropriate preloading can partially compensate for secondary compression settlements so that remaining settlements are tolerable. This conclusion is supported by reasoning and by laboratory tests, ${ }^{I}$ and, more importantly, by field results discussed in Reference $I$ and subsequently. 
Methods and Disturbance Effects

The relative merits of various methods for installing sand drains have been widely, and at times heatedly, discussed. As a result of much discussion and little research, the effects of installation method and even the merits of using sand drains often become an emotional matter, rather than merely a technical aspect, susceptible to investigation of the general technique of precompression to improve poor subsoils.

Since the first use of the precompression technique with vertical sand drains, the drains have been installed by the various methods listed below.

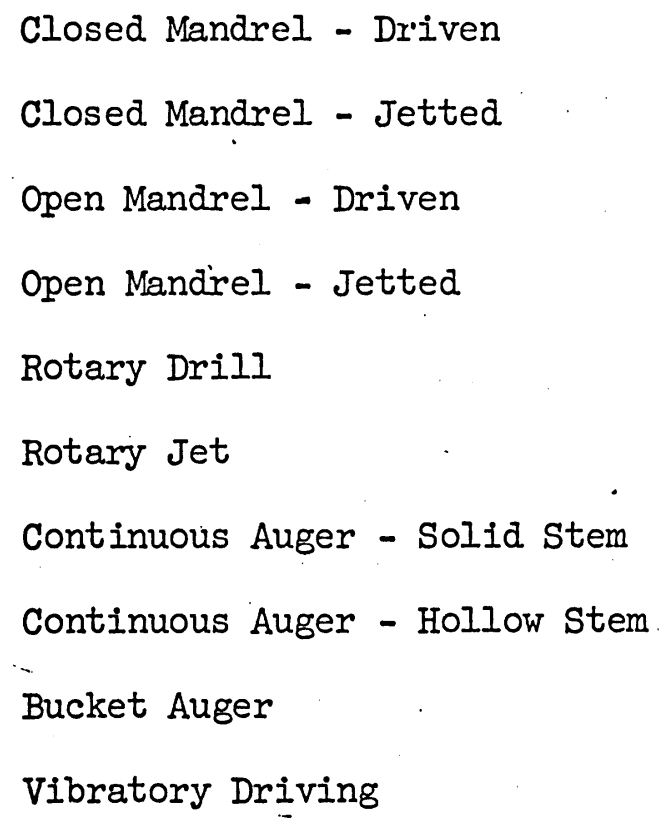

- Current interest is centered largely on: (I) the driven closed-end mandrel, which is by far the most common procedure; (2) a rotary jet, jetted mandrel or modification thereof; and (3) solid-and hollow-stem augers. The common driven mandrel procedure has developed into a highly efficient and relatively low-cost construction operation, although a news report ${ }^{29}$ on the first use in England of the Dutch jetting procedure states that 
"... sand drains installed with this system are reported

as approximately half the cost of traditional systems.

The time for completion can also be reduced to as low

as 20 percent of the time required for driven sand drains."

While this may be optimistic, it suggests that the cost may become competitive with driven drains. Various jetting installation techniques have been used intermittently for over 30 years. The hollow-stem auger (Fig. 10) developed by Landau, ${ }^{13}$ is a recent development. Alternatives to the driven mandrel are of special interest as possible means for avoiding soil disturbance.

When considering various installation techniques, an underlying consideration is that it is virtually impossible to install sand drains by any method without causing disturbance in the surrounding soil. Some possible disturbing effects are listed in Table 2.

Any installation method must cause some disturbing effects, just as disturbance results when obtaining even the best "undisturbed" soil samples. It is obvious, therefore, that primary interest must be focused upon assessing the severity of these effects on results obtained, rather than upon the question of whether disturbance does or does not exist. Despite the importance of installation methods on both the soil and the attitude of engineers and despite its potential significance in terms of dollar savings, adequate field tests comparing installation methods have not been performed to date, and the relative merits of various methods are still largely speculative.

Driven Mandrel-Type Sand Drains

Since the most common method for installing sand drains is the driven closedend mandrel procedure, it will be discussed first. It is impossible to conceive a worse method for installing sand drains than to drive a mandrel that is closed at the bottom into a soft soil, thereby displacing a volume of soil equal to the volume of the mandrel and causing both smear and disturbance from soil displacement. Since disturbance decreases the coefficient of consolidation 


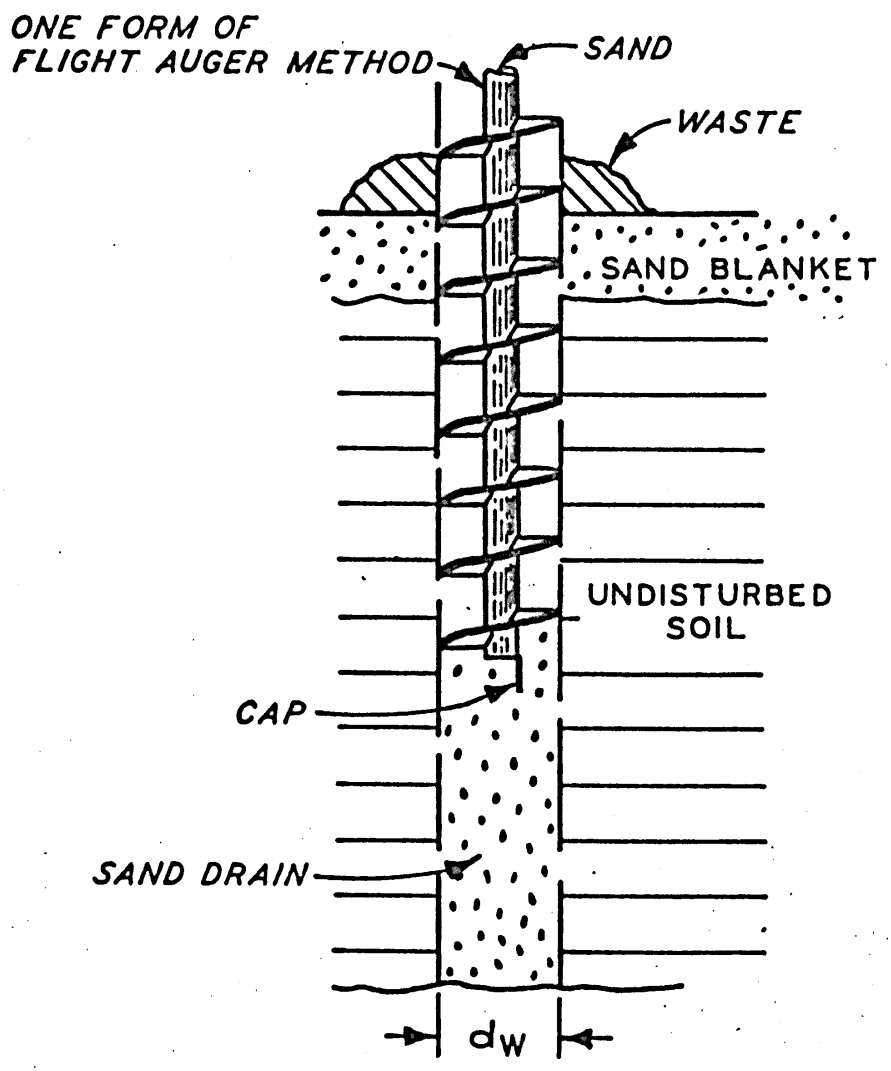

HOLLOW STEM AUGER FOR INSTALLING SAND DRAINS

(AFTER LANDAU) 
Disturbance Effect

1. Smear

2. Soil displacement and remolding effects

3. Grouting of thin sand layers

4. Thin film of mud on sides of drain

5. Contamination of sand backfill in drain

6. Distortion of thin sand layers
Remarks

Can be caused by any method of installation, even by a thin sharp knife drawn through soft clay

a. Outward soil displacement caused by driven closed-end mandrels

b. Inward soil displacement resulting from jetting methods or withdrawal of solid-stem augers

c. Either outward or inward soil displacement may result from hollow-stem auger methods, depending on rotation and advance rates of auger

Caused by natural drilling mud formed by jetting methods

Caused by natural drilling mud formed by jetting methods

Possible in jetting methods if washing during jetting is insufficient. Also possible when withdrawing driven mandrel if sand sticks in mandrel

Most likely with driven mandrel method, possible with solid- or hollow-stem augers. May be severe in varved or thinly bedded deposits 
and reduces the shear strength of the soil, it would seem that this installation method is surely the worst that could possibly be used; still, it has been used a great deal and is clean and highly efficient from a construction viewpoint. Also, it presents no difficult inspection problems. While a poorer method cannot be visualized, in order to be reasonably objective it seems appropriate to ask: how bad is it under field conditions compared to other methods? and are the effects as serious as they appear at first glance?

These questions lead to others, such as: (1) can beneficial results be obtained if displacement-type sand drains are used? (2) do other installation methods result in significantly improved performance? and (3) are other installation methods preferable even though more costly, and if so, what cost differential is appropriate?

Evidence of Soil Disturbance

It is well known that partial remolding decreases the coefficient of consolidation and increases soil compressibility so that settlement can occur even though the load is not increased. However, the relative importance of these effects decreases as the load on the soil is increased. Thus, for stresses moderately in excess of the original preconsolidation stress, the coefficient of consolidation and the equilibrium void ratio are only slightly lower than for a high-quality undisturbed sample, as shown in Fig. 11 (after Hansbo ${ }^{15}$ ). Furthermore, in contrast to what several authors have stated, the coefficient of secondary compression is not increased by disturbance; instead; it is decreased (see Fig. 12 of Reference 1).

When closed-end manörels are driven for sand drain installation, pore-water pressures increase, which is logical because soil displacement increases horizontal total stresses, probably to passive values, since some ground surface heaving normally occurs. The increased pore pressures are related to the soil shear strength, which generally increases with depth. Pore pressures from driving 


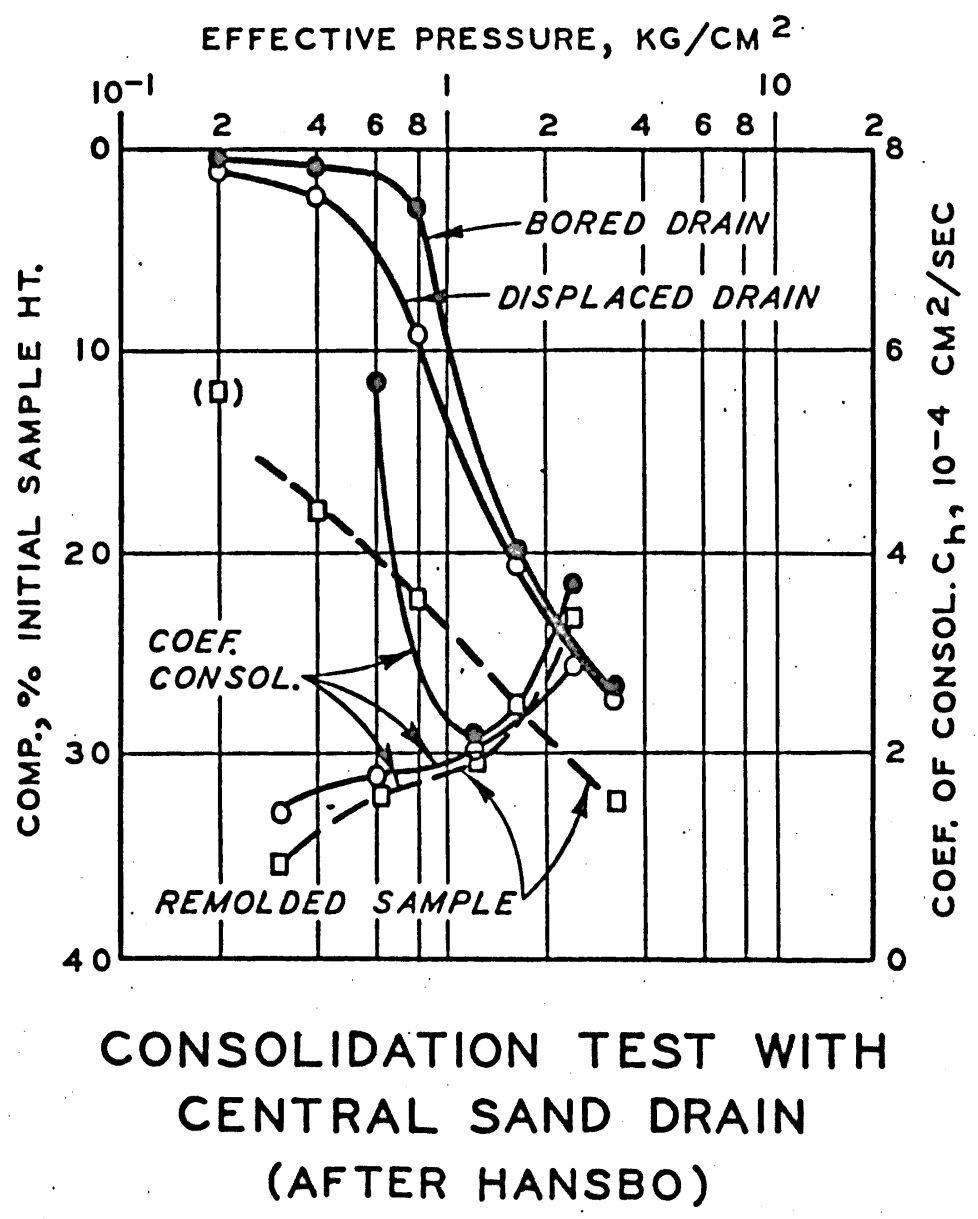




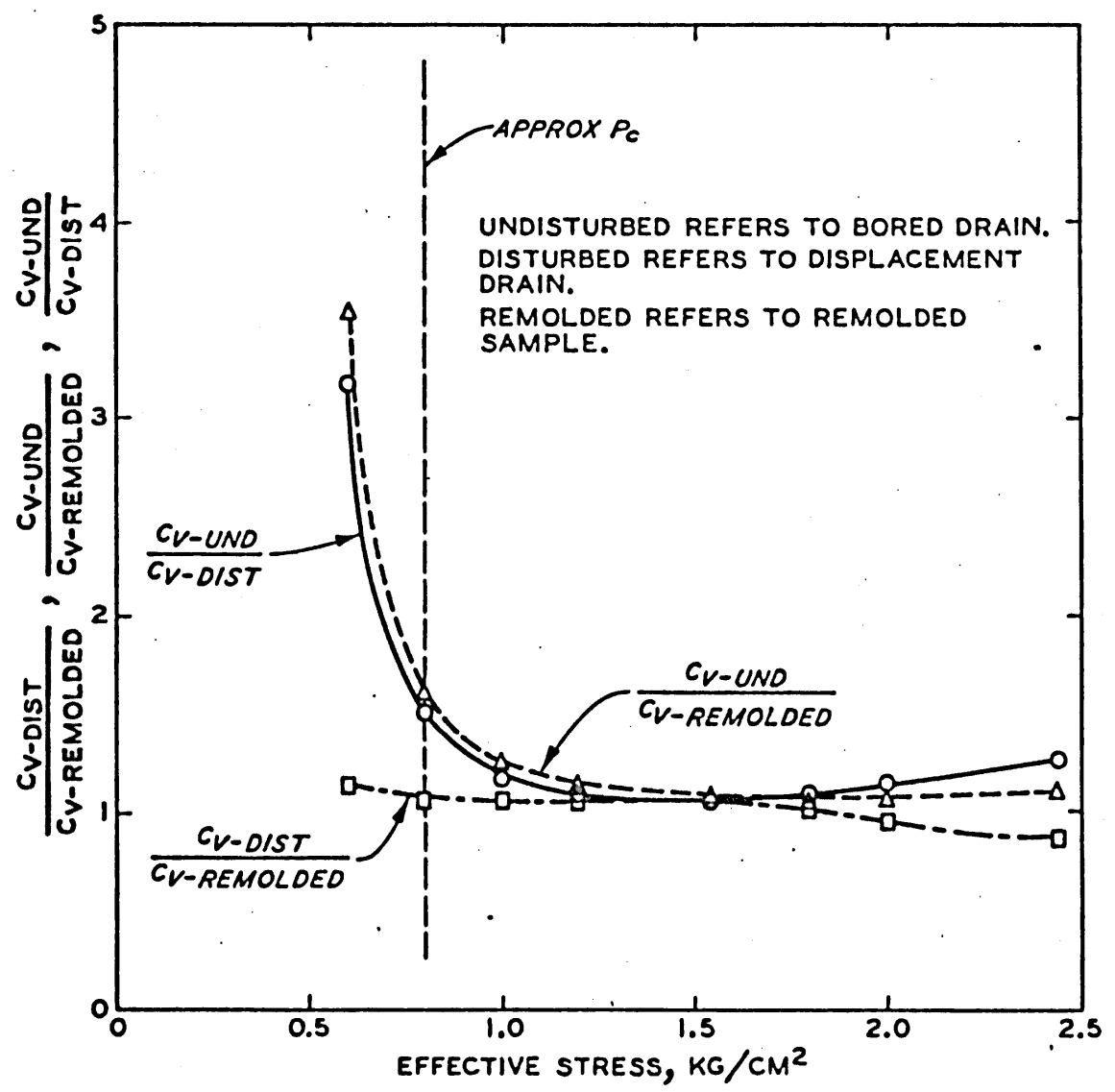

EFFECT OF DISTURBANCE AND VARIATION OF $C_{V}$ WITH EFFECTIVE STRESS (AFTER HANSBO) 
displacement mandrels dissipate in a few weeks or a month or two and are usually small during major fill-placement operations. The high pore pressures induced by displacement-type drains have often been cited as evidence of associated serious soil disturbance. However, as simons 30 pointed out, the increased pore-water pressures indicate only that total stresses have been increased and not necessarily that the soil has been disturbed. It is neceșary, therefore, to resort to other evidence for evaluating soil disturbance.

Iaboratory Tests. Laboratory tests simulating displacement- and nondisplacementtype sand drains have been reported by Hansbo, ${ }^{15}$ Simons, 30,31 and others. Hansbo performed consolidation tests simulating bored and displacement-type drains, with results as shown in Fig. 11. The $c_{v}$ data from this figure have been replotted as ratios versus effective stress in Fig. 12, from which it is evident that $c_{v}$ for the simulated displacement-type drain was decreased significantly; only in the immediate vicinity of the preconsolidation stress and was virtually unaffected at higher stress levels. The relative insensitivity of $c_{v}$ for this sensitive and soft clay soil to disturbance from installation of a simulated displacement-type drain and also to complete remolding for stress ranges of practical interest is rather surprising. Comparative tests on undisturbed and completely remolded soils, reported in the sand drain review, ${ }^{10}$ indicated that $c_{v}$ for good undisturbed samples was about three times that of completely remolded samples, but tests to simulate displacement-type sand drains were not performed. Other unpublished data indicate that this ratio varies from about. 1 to 6 , with an average value of about 3.5. Iaboratory tests of a soft grey silty marine clay with a sensitivity of 6 , reported by simons, 30,31 indicate that $c_{v}$ values for simulated displacement-type drains were 20 percent lower than for nondisplacement-type drains.

Pile Driving Experiences. Displacement-type drains are similar to closed cylindrical piles driven in soft clay, and it might be expected, therefore, 
that pile driving experiences would shed some insight on behavior of displacementtype sand drains. Much data exist to show that pile driving causes large porewater pressures and some reduction in shear strengths. However, the porewater.pressures generally dissipate in days to weeks, and the soil regains its original shear strength. Strength losses are not as severe as those caused by complete remolding; Orrje and Broms ${ }^{32}$ reported strength losses between 0 and 40 percent, averaging about 20 percent, at a distance of 1.1 ft from the pile surface for piles driven in a clay having a sensitivity of about 30 to 50 . Unfortunately, the effects of this degree of disturbance on $\mathrm{c}_{\mathrm{v}}$ of soil near the pile cannot be estimated. While these results were for widely spaced piles, the same authors ${ }^{32}$ also reported other data for a large pile foundation with relatively closely spaced reinforced concrete piles. They found that at the center of the pile group

"...the average undrained shear strength ... after the driving of the piles was approximately 90 percent of the initial shear strength measured before driving. ...These measurements indicate that the undrained shear strength will decrease only locally around the piles due to pile driving and that the average undrained shear strength is not affected appreciably even if piles are driven into a clay with a relatively high sensitivity ratio."

While average soil conditions between sand drains are important, the effects of disturbance of soil near the drain are far more significant. Unfortunately, pile driving experiences cannot be correlated with $\mathrm{c}_{\mathrm{v}}$ values for the disturbed soil in this area. The soil near the surface of a displacement drain must be disturbed, but pile driving experiences provide little direct insight into disturbance effects on $c_{v}$ as loading and consolidation occur.

Sand Drain Experiences. Despite the large number of sand drain installations, only scattered evidence is available concerning the effect of displacement-type sand drains on $\ddot{c}_{v}$ and practically no definitive comparisons have been made between this and the various types of nondisplacement drains. 
Simons ${ }^{33}$ reported no decreases in undrained shear strength resulting from driving a mandrel for sand drain installation, even though appreciable pore pressures were developed, but $c_{\mathrm{v}}$ effects were not evaluated. Strength decreases were found from installation of displacement-type drains in Sweden, 10 but effects on $c_{v}$ are not known. Hansbo ${ }^{15}$ reported detailed field observations on another sand drain installation in Sweden in a sensitive clay. Driving a closed-end mandrel for displacement-type sand drains resulted in a strength decrease of 20 to 40 percent of initial strengths. While the direct effect on $c_{v}$ is unknown, field values of $c_{v}$ were at least as large as obtained from consolidation tests on good undisturbed samples, but $c_{v}$ for the closest sand drain spacing was half that for wider spacing. Possibly, nondisplacement drains would have yielded higher $c_{v}$ values than found for any spacing of displacement drains, but this is not known. Results from careful tests by Schmidt and Gould ${ }^{34}$ indicate no significant effect of displacement-type sand drains on $c_{v}$ values under large preload stresses, but here again the evidence is of an indirect type. Agreement, or. lack thereof, between field and predicted results is not a satisfactory means for evaluating effects of displacementtype drains on subsoil consolidation characteristics because of the many variables involved and the difficulty of determining actual field properties. Summary Regarding Disturbance Effects. There can be little or no doubt that displacement-type sand drains cause some soll disturbance near the drains and possibly throughout a sand-drained area. However, the ultimate effects of soil disturbance on $c_{v}$ and behavior of a sand-drained area are not obvious, partly because of the increased loading placed on a sand-drained area, which tends to minimize the effects of disturbance on $c_{v}$. Definitive evidence of the effects of using displacement-type sand drains relative to other types can be obtained only by comparative installations of displacement and of nondisplacement 
types in a variety of soil conditions. While such installations have not been reported, one such comparative test installation is now in progress, according to Aldrich, 35 but results have not been released.

While disturbance effects from driven closed-end mandrels are relatively obvious, other installation methods may account for other types of disturbance, as discussed previously, that are less apparent. This is suggested by the care required to install pressure-relief wells, wellpoint systems, and water-supply wells by jetting methods. "Mudding off" of pervious layers and of the walls of the drain may be difficult to avoid, especially when jetting through a pipe that nearly fills the hole being made. Also, according to Boutsma and Horvat, 36 cracks in a vertical plane have been found to connect sand drains installed by bailing action of a heavy jetting pipe in Holland. The possibility is advanced that high-water pressures were caused by the bailing action, forcing open the soil, as occurs during grouting with high pressures. While these cracks had an unknown effect on $c_{v}$, this use of sand drains apparently was successful. However, the cracks appeared to cause progressive movements of an excavated slope.

It is not yet known if the lesser disturbance effects from nondisplacement methods will result in significantly improved field performance, nor is it known if the rapid consolidation of soil around the walls of any drain will act as a "smeared zone," or zone of substantially reduced permeability. It seems possible that this latter effect plus true disturbance effects from even the best nondisplacement installation procedure may tend to minimize the-effect of drain installation method. This is possible because, as has been discussed, the effects of disturbance decrease with increasing effective stress. Selection of Installation Procedure

It is believed safe to conclude that the driven mandrel method, if used with low design loadings, w1ll cause slower consolidation and more settlement than 
if the soil were completely undisturbed. Despite this, where added loadings are small, driven mandrel-type sand drains should have net beneficial effects, as compared to omitting them, because of additional drainage paths provided. Furthermore, where added loads are substantial, and this is generally the case, the additional settlement and the decrease in the coefficient of consolidation may be negligible and of little practical importance.

For practical design purposes, using driven mandrel-type sand drains, all evidence examined indicates that field behavior will be at least as favorable as predicted using the coefficient of consolidation obtained from laboratory consolidation tests on the best quality undisturbed samples without consideration of smear or disturbance, provided the design value is selected for close to maximum effective stresses. However, where subsoil conditions are nonuniform and contain layers, even though thin, of sand or silt that may provide effective intermediate drainage, the average coefficient of permeability in a horizontal direction will exceed that in a vertical direction, and field permeability tests or laboratory tests on large samples are desirable. Field test results should be adjusted to correspond to maximum loading conditions.

Nondisplacement installation procedures should prove advantageous in varved and other stratified formations and of somewhat lesser advantage in relatively uniform deposits with substantial preloads. However, the various nondisplacement procedures can hardly be expected to be equal. Nondisplacement methods for installing sand drains, such as jetted or hollow-stem augers, may be more economical than displacement-type drains if they result in significantly less smear and disturbance, even though they cost more per foot. However, these patential benefits cannot be given a high value until comparative field tests have been made; such tests have not been made to date.

While the nondisplacement methods are attractive in principle, construction 
and inspection requirements are believed more demanding, and their behavior relative to displacement-type drains must be ascertained under normal field conditions. Comparative field installations of various types of sand drains would have much meaning if done at a site where effective surcharge loadings are substantial relative to the preconsolidation stress, because this is the usual case. If done at a site where effective surcharge loadings are equal to or less than preconsolidation stresses, misleading results would probably be obtained. In fact, at such a site sand drain spacing and installation differences would probably have no significant effects, and sand drains would function only as an added safety factor against unforeseen conditions.

Because the method used for installing sand drains is merely a detail in the precompression technique, it should not be permitted to dominate consideration of applicability of the precompression concept with sand drains. Commercially available sand drain installation methods include a sufficient variety to accommodate any subjective convictions of the engi neer responsible for the design. It is hoped that additional badly needed comparative tests will be made under a variety of subsoil conditions as part of actual. construction work. Tests should be performed under research conditions, even though they may be nonrepresentative of some field installation results, because of the extreme importance of quality of inspection on completed sand drains. 
Numerous examples are available that illustrate results achieved from using sand drains. In reality, these cases illustrate results using preloading to achieve precompression, for sand drains are only a servant to the precompression concept. A few random examples are discussed below. While these present satisfactory results achieved where design and field supervision were competent, numerous installations have been attempted that were unsuccessful. These are not discussed because in every instance in which sufficient data were available to permit analysis of the project, the unsuccessful behavior could have been expected in advance of construction or was caused by improper construction inspection. Most of these failures occurred during the development phase of sand drain usage.

-

Field results indicate rather conclusively that sand drains serve a useful purpose where properly used. All data indicate the extreme importance of determining in detail the subsoil profile and giving special attention to possible drainage layers, subsoil consolidation characteristics, and preconsolidation stresses and stability. However, it should be clearly understood that the ultimate success of precompression with sand drains depends upon competent field supervision and a willingness and ability to modify the work to conform to actual field conditions, should this become necessary. It is normally impossible to make sufficiently detailed investigations prior to construction to avoid a "confirm-as-you-go" approach.

New York State Highway Department

According to Moore, 37 the highway department of the State of New York has often used sand drains, after careful explorations, testing, and design studies. Time-settlement plots shown in Fig. 13 for a preload fill in Syracuse, N. Y. 17 and pore-pressure plots shown in Fig. 14 indicate that theoretical and actual 


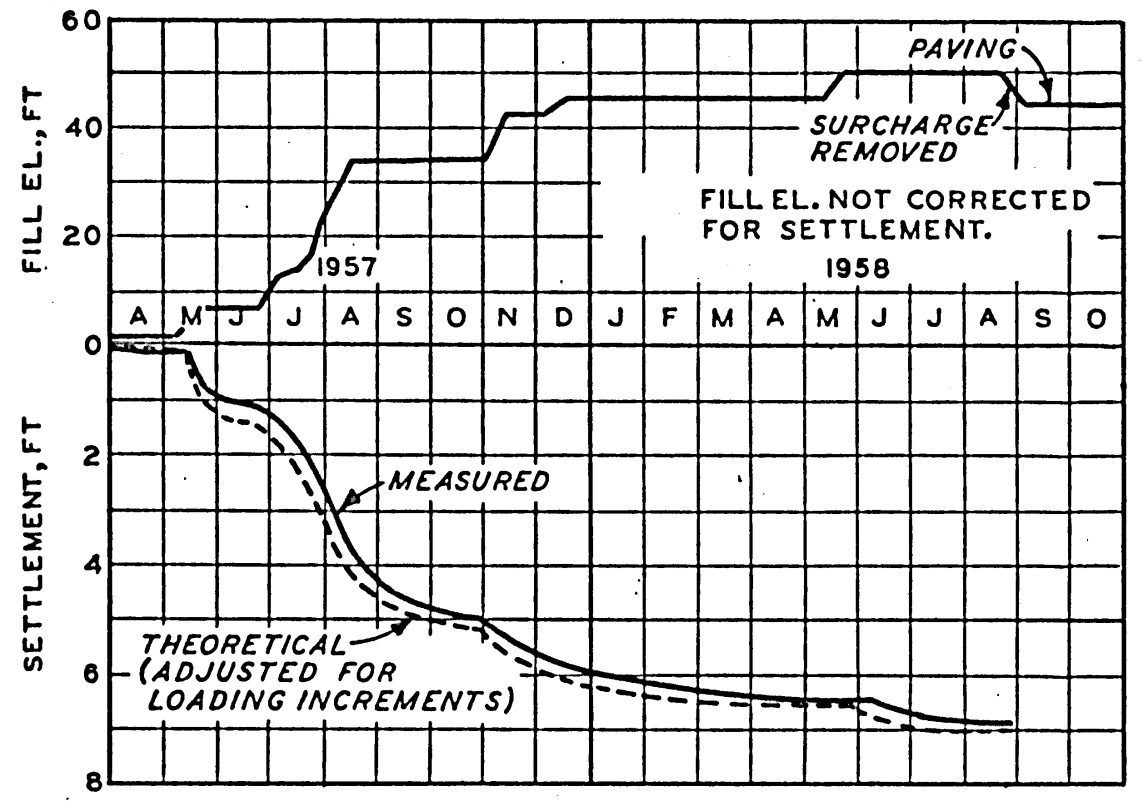

SETTLEMENTS WITH SURCHARGE FILL WITH SAND DRAINS

TIME-RATE PLOT FOR FILL CONSTRUCTION AND SETTLEMENT, OSWEGO BLVD., SYRACUSE, N.Y. (AFTER L. H. MOORE) 


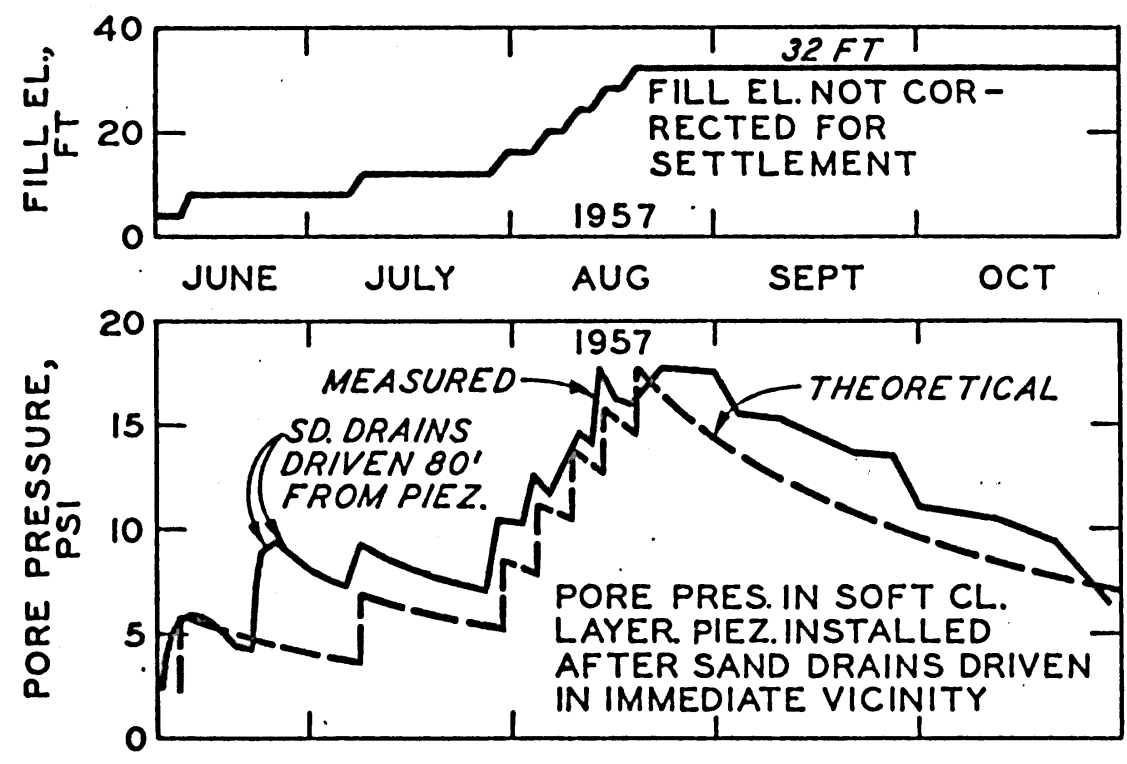

PORE PRESSURE- DISSIPATION

SURCHARGE FILL WITH SAND DRAINS.

TIME-RATE PLOT FOR FILL CONSTRUCTION AND PORE PRESSURES, OSWEGO BLVD., SYRACUSE, N.Y.

(AFTER L.H. MOORE) 
results agreed closely. The decreases in moisture contents that occurred are shown in Fig. 15. Precompression, with displacement-type sand drains, reduced moisture contents in: (1) soft clay from about 40 to 20 percent, (2) marl from about 70 to 45 percent, and (3) peat from 210 to 140 percent. While the need for sand drains cannot be evaluated from these data, it appears that the precompression technique with displacement-type sand drains was highly beneficial and that settlements were not increased by use of displacement-type drains. Schmidt and Gould

An unusually thorough investigation of precompression results was reported recently by Schmidt and Gould $3^{44}$ in which they described a sand drain application in a large practically submerged tidal swamp near Wilmington, Del. Borings were made before and after precompression, and undisturbed samples were tested to determine strength and consolidation characteristics. In addition, field values for the coefficient of consolidation were computed from piezometer observations. The results (see Figs. 16 and 17) demonstrate that disturbance from displacement-type sand drains definitely occurred but was not especially significant because effective surcharge loadings were significantly higher than preconsolidation stresses. The drop in field $c_{v}$ with increasing effective stress was found at some locations but not at others. The results of the before and after testing are sumarized in Fig. 18, and their conclusions are summarized in Fig. 19. The reported results have special interest because the work was done in a swampy area having subsoils of Iow shear strengths and low coefficients of compressibility. While the results do not clearly identify the contribution of the sand drains, they clearly show the marked beneficial effects of the precompression technique with displacement-type sand drains in: (I) decreasing water contents, (2) increasing shear strengths, (3) causing settlements to occur during surcharge loading, and (4) increasing indicated preconsolidation stresses 


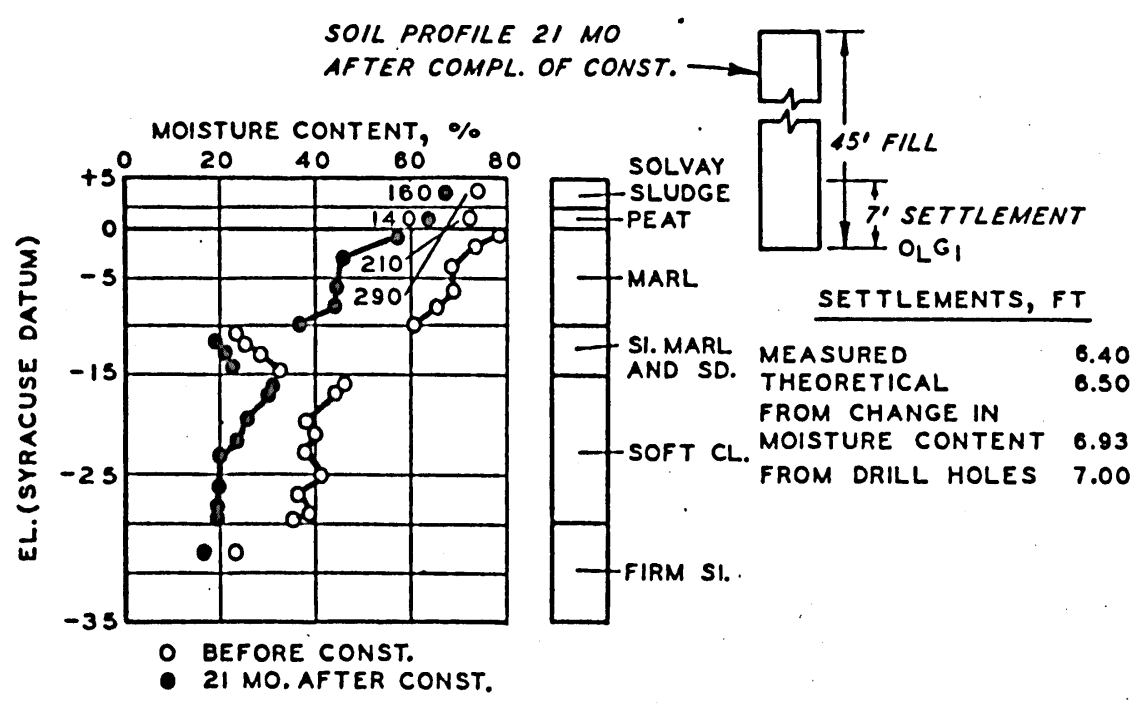

SETTLEMENTS AND MOISTURE CONTENT DECREASE SURCHARGE FILL WITH SAND DRAINS

OSWEGO BLVD., SYRACUSE, N.Y.

(AFTER L. H. MOORE) 


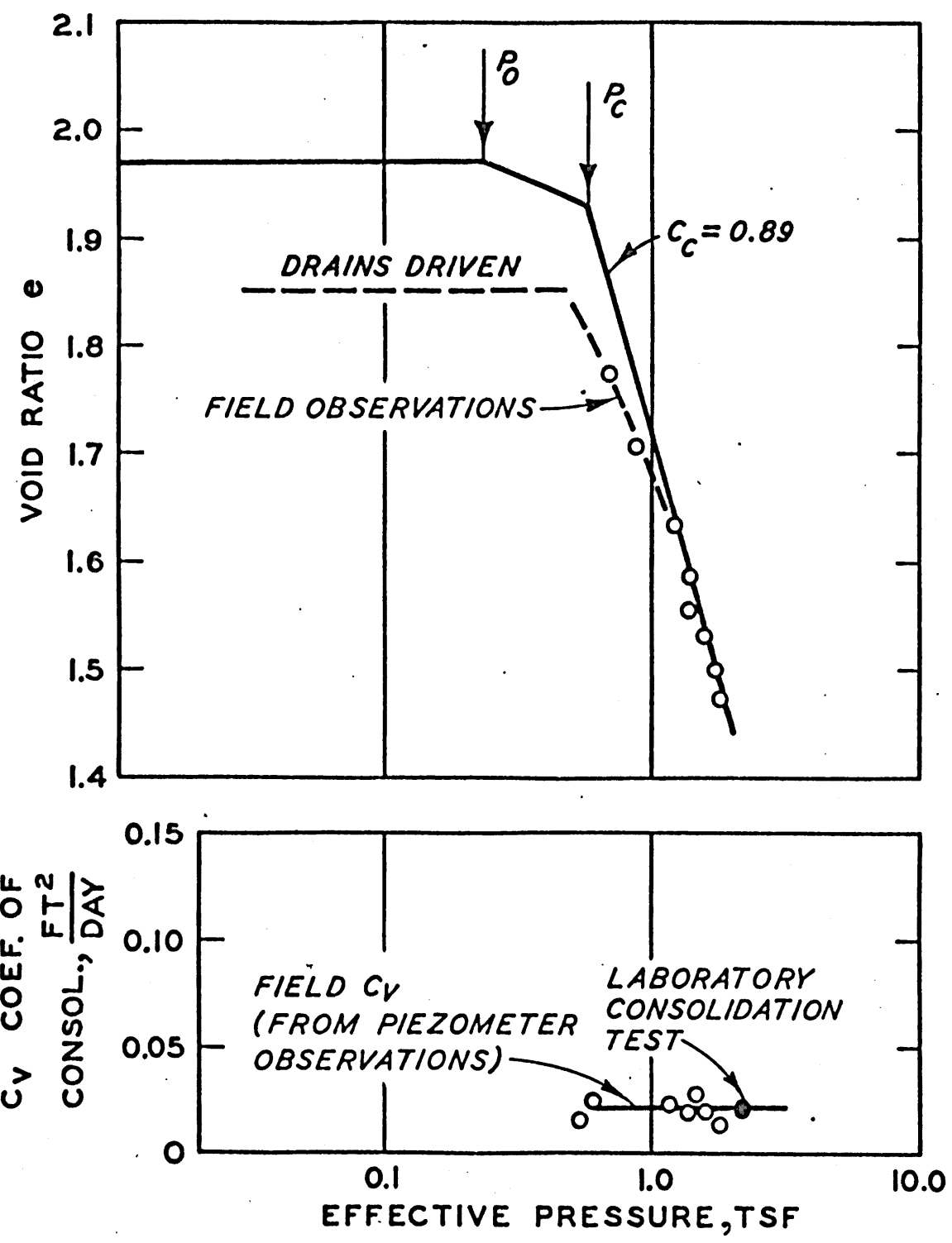

COMPARISON OF FIELD AND LABORATORY DETERMINED VALUES FOR $e, C_{C}$ AND $C_{V}$

(AFTER SCHMIDT \& GOULD, 1968, PIEZ. PI3 \& PI3A) 

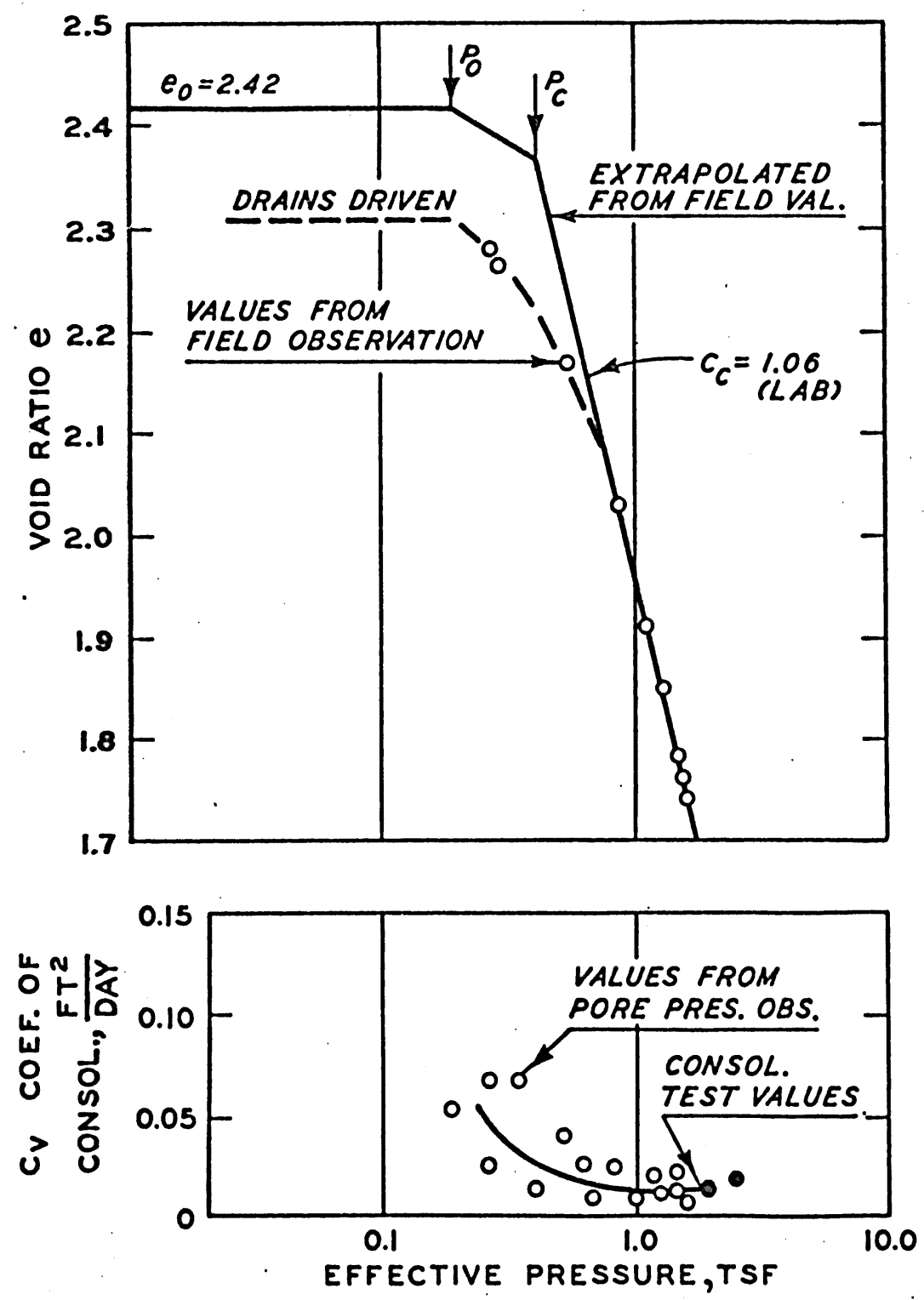

COMPARISON OF FIELD AND

LABORATORY DETERMINED VALUES

FOR $e, C_{C}$ AND $C_{V}$

(AFTER SCHMIDT \& GOULD, 1968, PIEZ. P 2 \& P 2 A) 
EFFECTS OF SURCHARGE LOADING WITH SAND DRAINS DETERMINED FROM "BEFORE" AND "AFTER" UNDISTURBED RORINGS AND TESTING (ACCORDING TO SCHMIDT AND GOULD, 1968)

\begin{tabular}{|c|c|c|c|}
\hline SOIL PROPERTY & $\begin{array}{l}\text { PRECONSTRUCTION } \\
\text { VALUE } \\
\end{array}$ & $\begin{array}{c}\text { AFTER } \\
\text { SURCHARGE } \\
\text { LOADING } \\
\end{array}$ & CHANGE \\
\hline WATER CONTENTS, AYG & $84 \%$ & $62 \%$ & $-22 \%^{*}$ \\
\hline VOID RATIO, AVG & 2.20 & 1.62 & $-0.58^{* *}$ \\
\hline SHEAR STRENGTH & 350 PSF & 920 PSF & +570 PSF \\
\hline$\frac{c}{p_{c}}$ & 0.30 & 0.29 & $\cdots$ \\
\hline$\frac{\Delta c}{\Delta p}$ & $\because$ & -・ & 0.28 \\
\hline COMPRESSION INDEX, $c_{c}$ & 0.95 & 0.94 & $\because$ \\
\hline
\end{tabular}

FIG. 18 
FINDINGS FROM "BEFORE" AND "AFTER" BORINGS AND TESTING AND FROM FIELD OBSERVATIONS.- SURCHARGE LOADING WITH SAND DRAINS (ACCORDING TO SCHMIDT AND GOULO)

\section{STRENGTH GAIN}

1. "... THE inevitable damage to StREngth bY DISPLACEMENT DRIVING has beEN COMPENSATED BY COMPRESSION AT HIGH EFFECTIVE STRESS."

\section{TOTAL SETTLEMENT}

2. ". . TOTAL SETTLEMENT CAN BE COMPUTED WITH REASONABLE ACCURACY FROM CON. VENTIONAL TESTS ON UNDISTURBED SAMPLES ... WHERE LOADING EXTENDS FAR INTO THE VIRGIN COMPRESSION RANGE."

3. "DISPLACEMENT DRIVING OF DRAINS APPEARS TO HAVंE INCREASED THE aMOUNT OF SETTLEMENT IN THE EARLY STAGES OF LOAD TRANSFER WITHOUT ALTERING THE FINAL EQUILIBRIUM VOID RATIO UNDER HIGH LOADS."

TIME RATE OF CONSOLIDATION

4. "... A $c_{v}$ VAlue computed from ... Early rapid setTlement ... Cannot be UTILIZED ALONE TO EXTRAPOLATE RATES OF CONSOLIDATION AND TIMES FOR SUR. CHARGE REMOVAL."

5. "DISTURBANCE BY DISPLACEMENT DRIVING APPEARS TO REDUCE SUBSTANTIALLY THE HIGH $C_{V}$ VALUES IN THE RECOMPRESSION RANGE DETERMINED FROM LABORATORY TESTS .... $C_{Y}$ VALUES UNDER HIGHER LOADS WELL WITHIN THE RECOMPRESSION RANGE APPEAR TO BE LITTLE ALTERED BY THIS FIELD CONDITION."

\section{DESIGN}

6. "... A PRECISE SAND DRAIN DESIGN EMPLOYING A CAREFULLY DETERMINED RATIO OF VERTICAL AND HORIZONTAL COEFFICIENTS OF CONSOLIDATION WITH AN ALLOWANCE FOR SMEAR OR DISTURBANCE IS DIFFICULT TO JUSTIFY FOR ORGANIC SOILS OF THE TYPE TESTED HERE AND FOR CONVENTIONAL METHODS OF INSTALLATION.

7. "THE PROCEDURE UTILIZED IN THIS DESIGN, WHEREIN AN AVERAGe VerTICAL CO. EFFICIENT OF CONSOLIDATION IS UTILIZED WITH NO ALLOWANCE FOR SMEAR, (OR DISTURBANCE) APPEARS APPROPRIATE." "... THE C $C_{y}$ VALUE MUST BE SELECTED CONSERVATIVELY, GENERALLY DISREGARDING ... THE HIGHER COEFFICIENTS GIVEN IN THE RECOMPRESSION RANGE BY BETTER QUALITY LABORATORY TESTS." 
in laboratory consolidation tests. Furthermore, it is evident that displacementtype sand drains did not increase total settlements. The time rate of consolidation closely checked expected results.

Hansbo - Sweden

A third and especially illustrative example of use of sand drains is the test fills at Ska-Edeby in Sweden, as described by Hansbo. ${ }^{15}$ This reference contains a wealth of valuable information and is recommended for serious study as illustrative of results in sensitive clay with relatively small fill loadings. Test fills were constructed without sand drains and with displacement-type sand drains at three spacings (see Fig. 20). Laboratory consolidation tests simulating a displacement-type sand drain showed significant disturbance effects on both compressibility and on the coefficient of consolidation at low stresses but negligible effects at high stresses (see Fig. Il), despite the sensitivity of the clay. Field results showed definite benefits of closer drain spacing (see Fig.2l) and of the benefits of sand drains versus no sand drains, compare Sections II and IV in Fig. 22. This installation had total applied fill loadings of about $540 \mathrm{psf}$ in test areas I, II, and IV and 780 psf in test area III, and results represent effects of relatively small applied loadings.

Displacement-type drains caused large increases in pore-water pressures and soil heaving between drains. Nevertheless, field time rate of consolidation results shows benefits of closer drain spacing generally about as expected; although for the closest drain spacing, $n=\frac{d_{e}}{d_{w}}=5$, the field value was about half that for wider drain spacings having $n$ values of about 9 and 13. Despite the low $n$ value for the closest drain spacing and the fact that displacementtype drains were used, the field value for $c_{v}$ was about the same as that obtained from conventional laboratory tests on good undisturbed samples. Somewhat surprisingly, field results indicate that final estimated settlements for the area 
VERY SOFT CLAY: SENSITIVITY ABOUT 10, RANGE $=5-15$

LIQUID LIMIT $=70-140$

PLASTIC LIMIT $=20-30$

WATER CONTENT $=$ OR $>$ LIQUID LIMIT

SHEAR STRENGTH $=100-200$ PSF

$C_{V} \simeq 0.01 \mathrm{FT}^{2} / D A Y(0.005-0.02)$

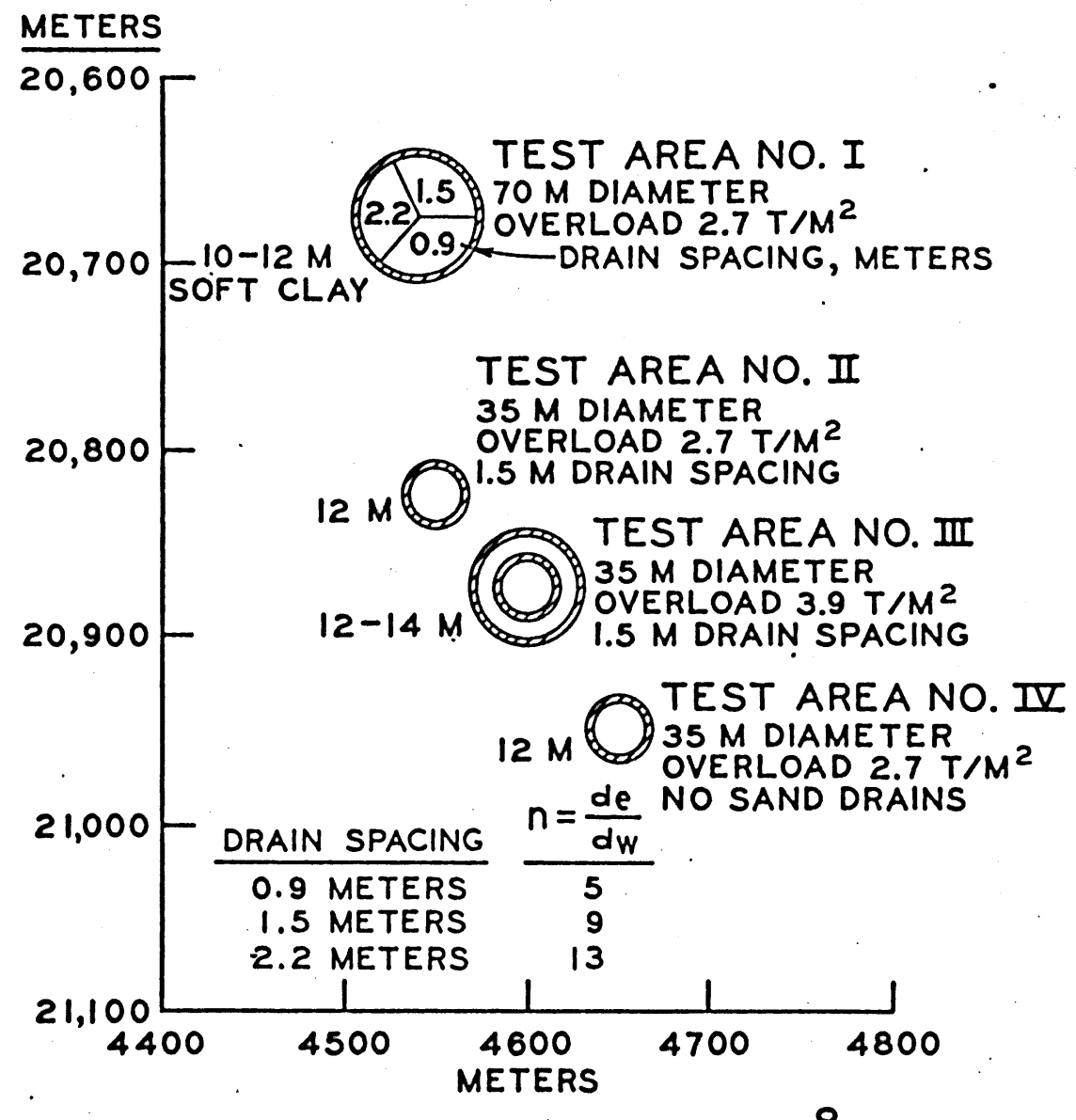

PLAN OF TEST AREAS AT SKA-EDEBY

(AFTER HANSBO) 


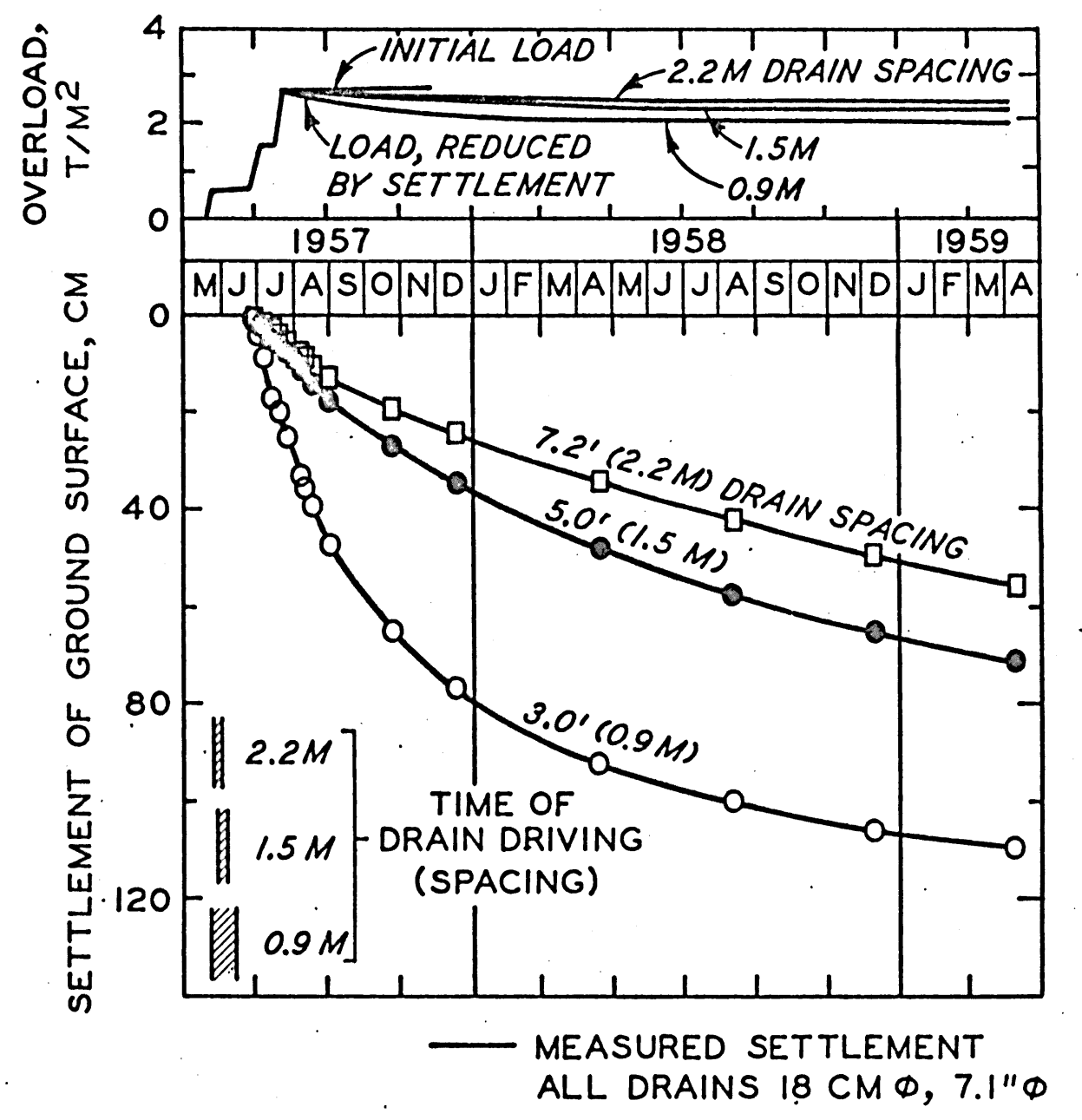

EFFECT OF SAND DRAIN SPACING

(AFTER HANSBO)

TEST AREA I 




\section{EFFECT OF FILL THICKNESS \\ AREAS WITH AND WITHOUT SD. DRAINS (AFTER HANSBO) \\ TEST AREAS II TO IV}


having the closest drain spacing, $\mathrm{n}=5$, were about the same as for wider drain spacings for the same applied load, indicating that disturbance effects at the closest drain spacing were not significantly more than at the wider spacings. Considerable lateral soil displacement occurred and evidently accounts for the settlement measured at test area IV (no sand drains).without apparent pore-pressure dissipation. The beneficial effects of even close displacement drain spacings $(n=5)$ in this sensitive soil are most interesting and indicate that disturbance effects from displacement-type sand drains were not as significant as would have been expected. Nevertheless, more rapid consolidation rates might have occurred with nondisplacement drains. Parsons ${ }^{38}$ - New Haven, Conn.

Precompression with vertical sand drains to accelerate consolidation was used to stabilize a soft organic silty clay in a former bay of Long Island Sound in which part of the area was initially under water and the compressible stratum of soft organic silty clay was as thick as $40 \mathrm{ft}$. Several long concrete block buildings (see Fig. 23) and a large manufacturing plant about 480 by 720 ft (see Fig. 24) are supported on spread footings on compacted sand fill placed over areas which were precompressed by surcharge fills using displacement-type sand drains. This work is of special interest because: (I) displacement-type sand drains were used in sensitive weak and compressible soil, (2) floor loadings were variable and in some areas quite heavy, (3) thorough design studies were made and especially competent construction inspection was provided, and (4) the design was made to compensate for all primary compression and a portion of secondary compression using procedures as summarized herein and in Reference 1. In effect, despite the unfavorable soll conditions, everything that would now be considered to represent the füll present development of precompression design was incorporated in this project, although additional borings would have been 


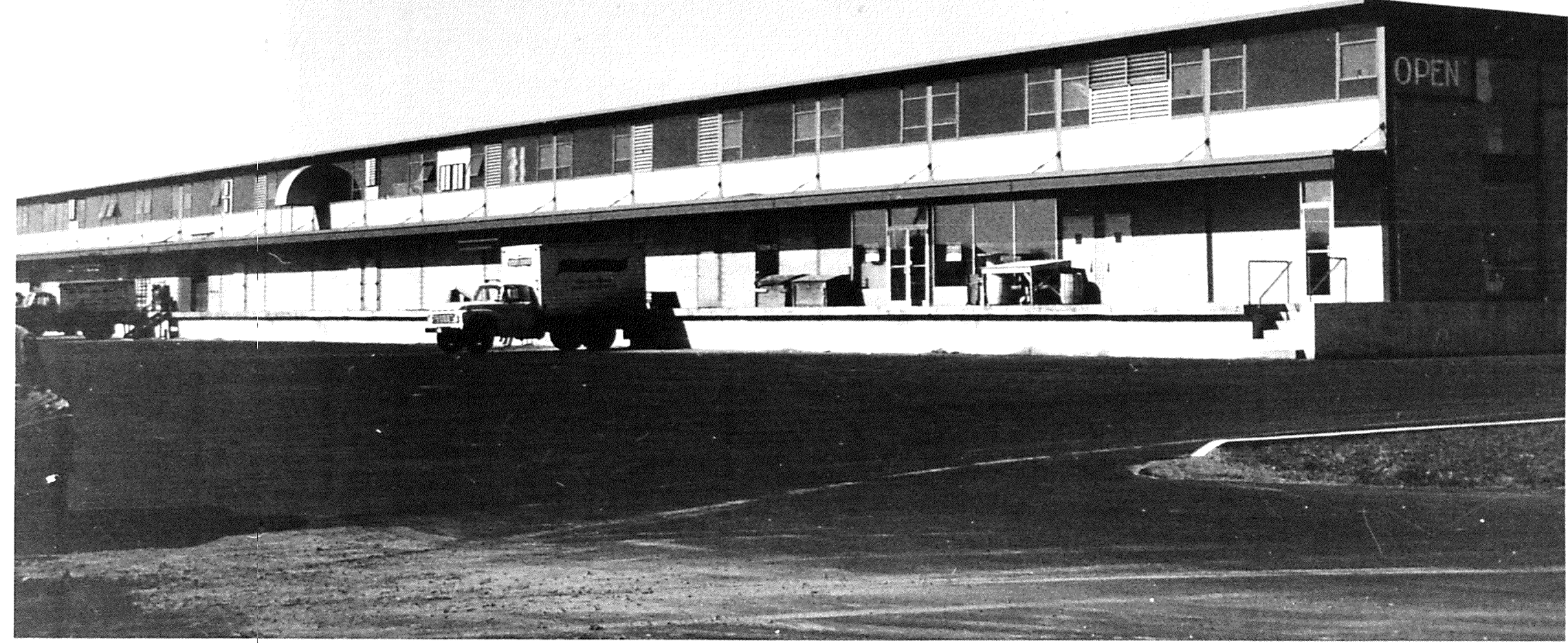




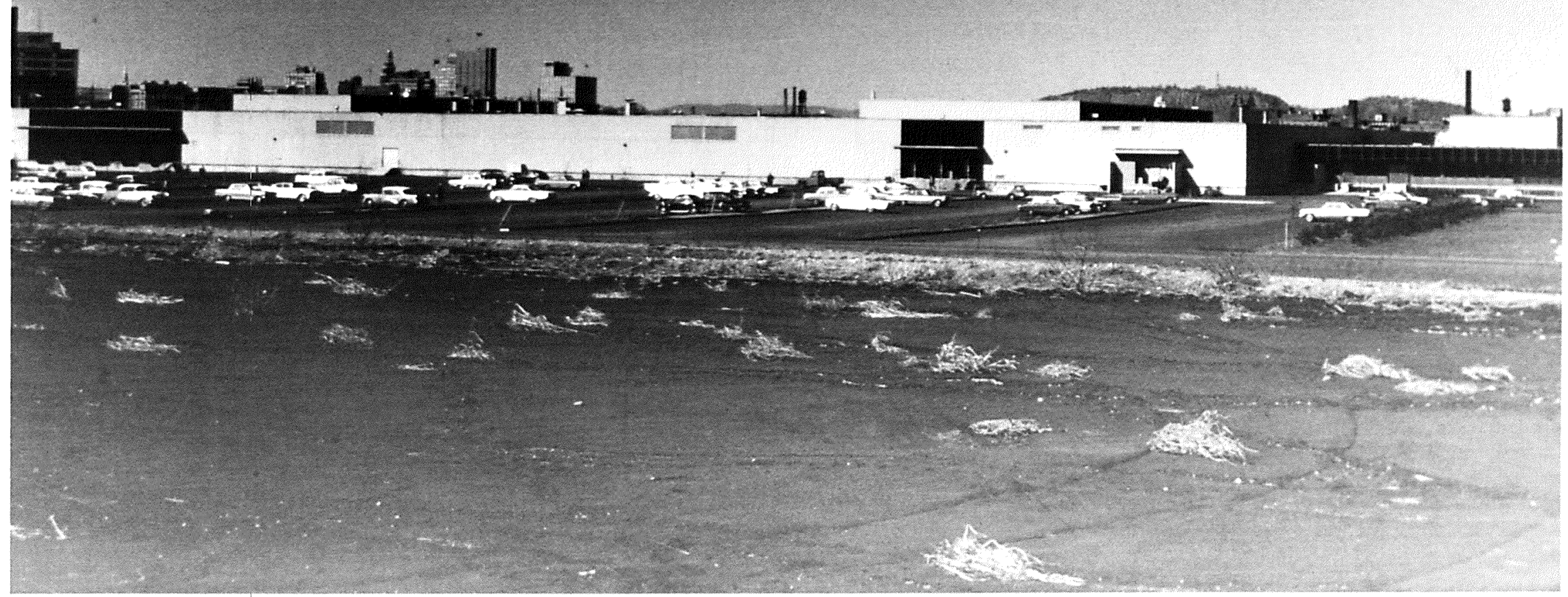


most valuable. This project represents a severe test of the present state-ofthe-art of precompression design.

Immediately adjacent to the site is the Connecticut Toll Road, which was completed using displacement-type sand drains after jetted sand drains were disrupted by fill shear failures. Views of completed structures are shown in Figs. 23 and 24, and a plan of the large single building (see Fig. 24) with fill elevations, surcharge thicknesses, and settlement prior to surcharge removal is shown in Fig. 25. Fill loadings and settlement records for three locations along the center of the building are shown in Fig. 26, and loadings and postconstruction settlements are shown in Fig. 27.

The large settlements during preloading, as much as $7 \mathrm{ft}$, and the negligible and relatively uniform postconstruction settlement (see Fig. 27) indicate that the precompression work met every expectation. The results demonstrate conclusively the ability of the precompression technique with displacement-type sand drains to eliminate large primary consolidation settlements that would otherwise occur and to reduce secondary compression settlements to unimportant and easily tolerable magnitudes.

Aboshi and Monden 39 - Toya Quay Wall, Japan

This application of precompression with sand drains is especially interesting because: (I) it was used to stabilize a normally consolidated soft clay to permit construction of a quay walf, as indicated by a typical section in Fig. 28, and (2) only partially penetrating sand drains were used. The soil had a liquid IImit of III, a plastic limit of 48, and natural water contents of 74 to 65 percent. A plan of the area and loading and time settlement curves are shown in Fig. 29.

Laboratory consolidation tests were performed in both consolidation and triaxial compression devices, modified to permit radial drainage toward a 

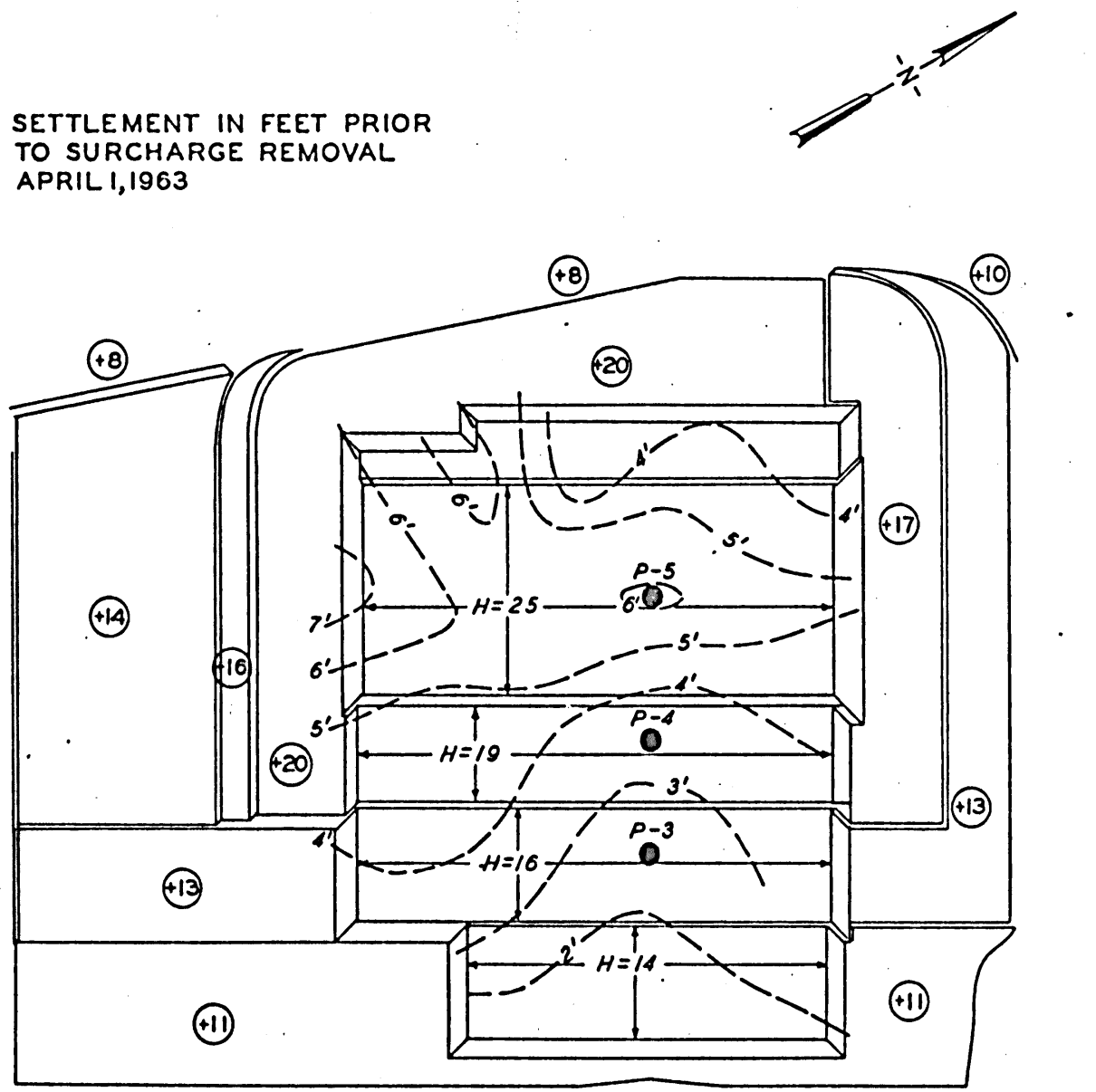

SARGENT BUILDING AREA

(AFTER PARSONS) 


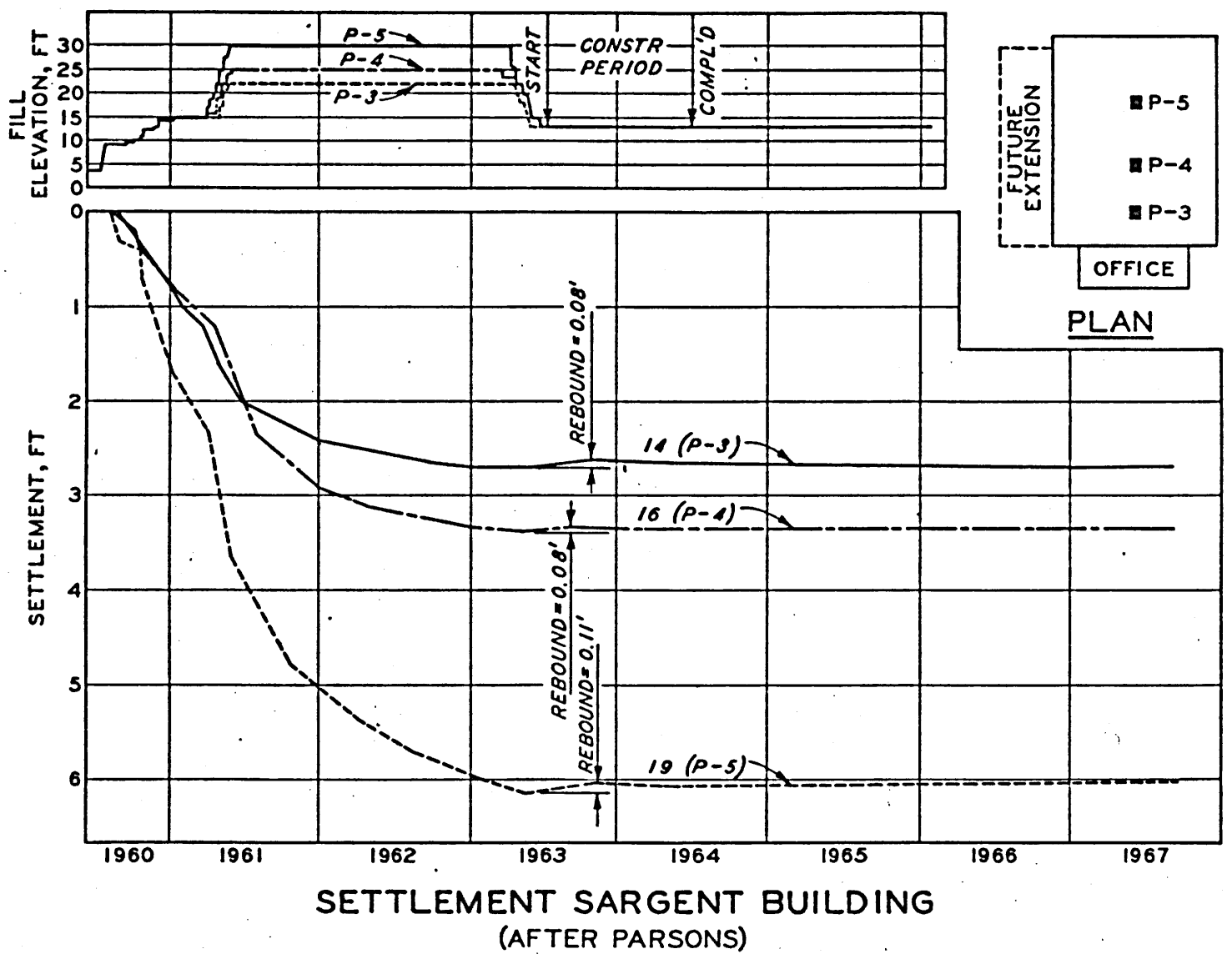




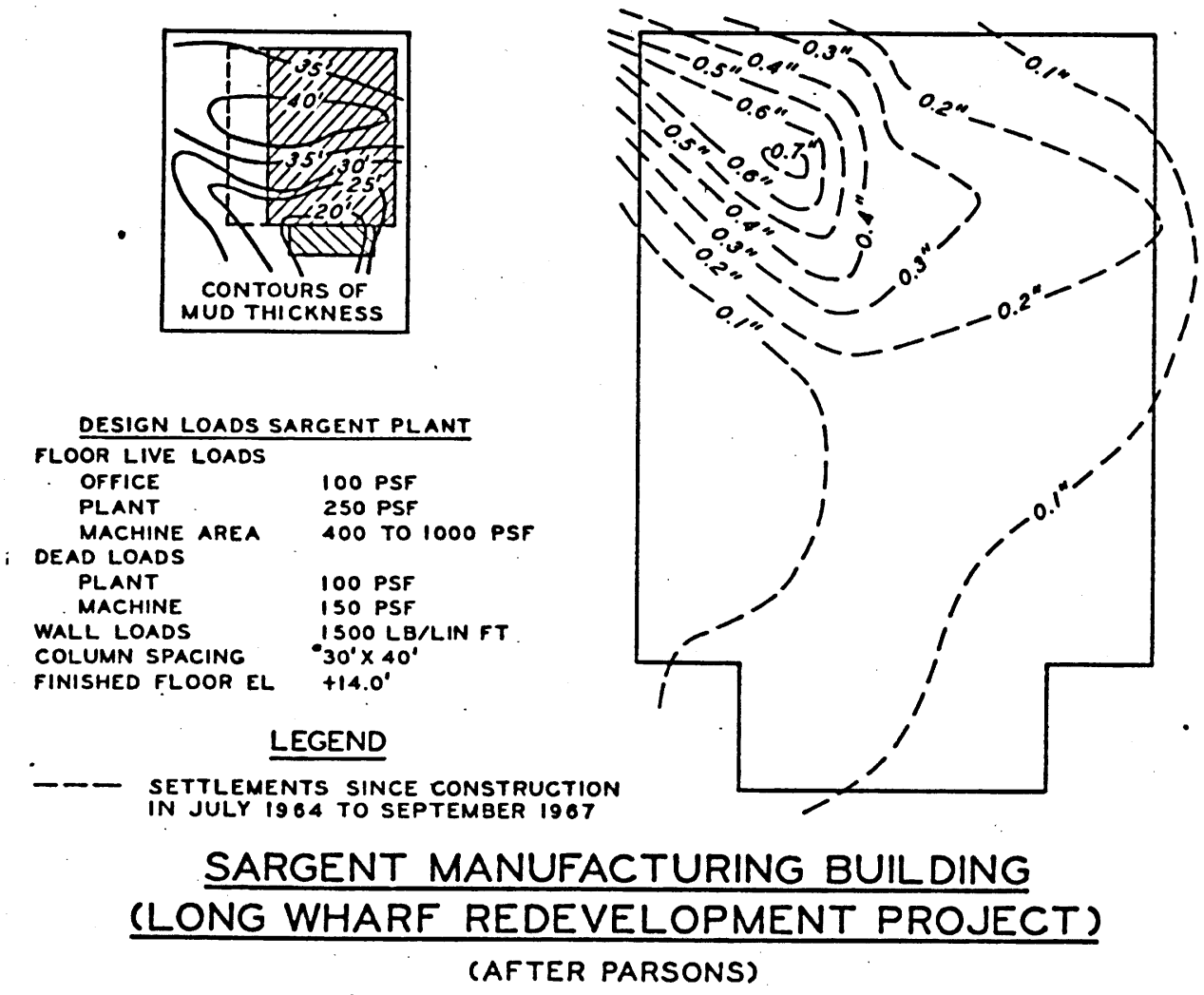

20
0
0 


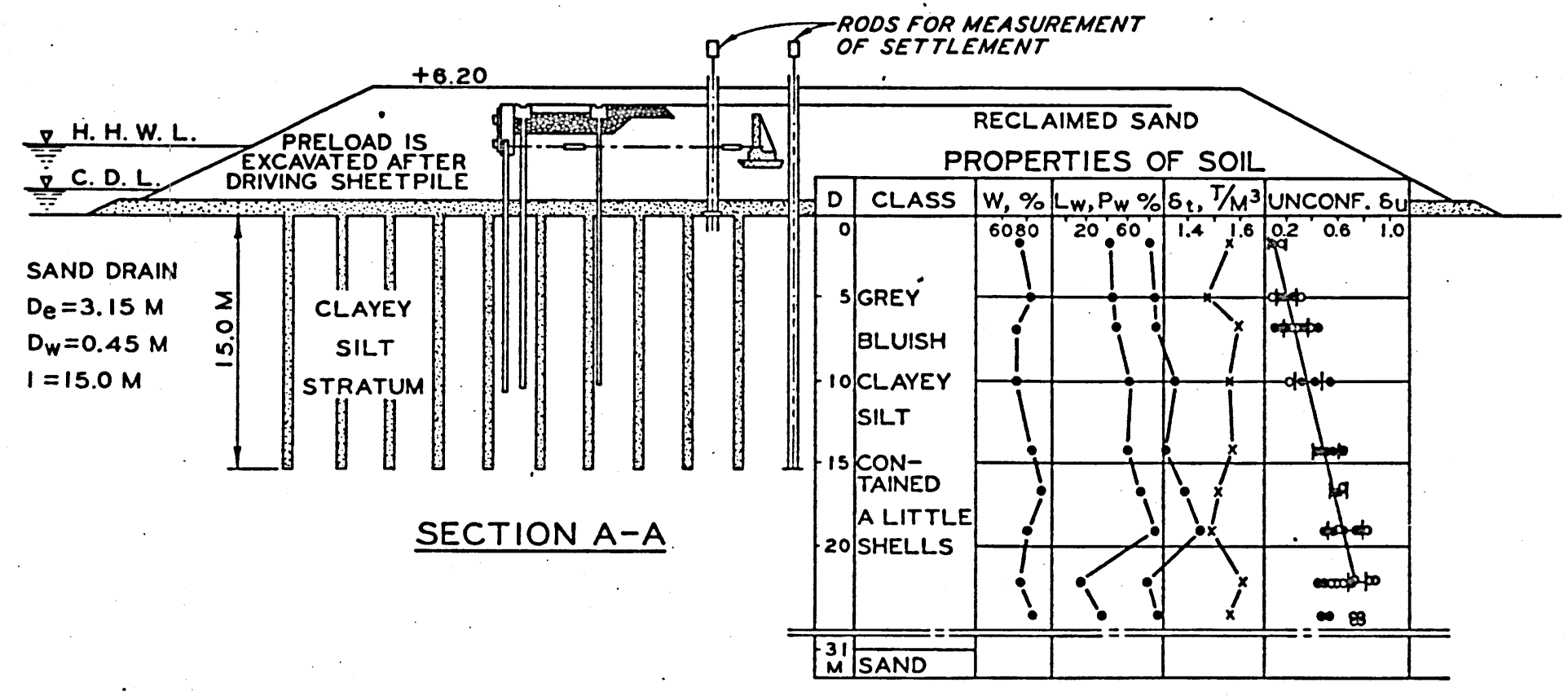

A SECTION SHOWING SAND DRAIN WELLS AND SUBSOIL CONDITIONS (AFTER ABOSHI AND MONDEN) 


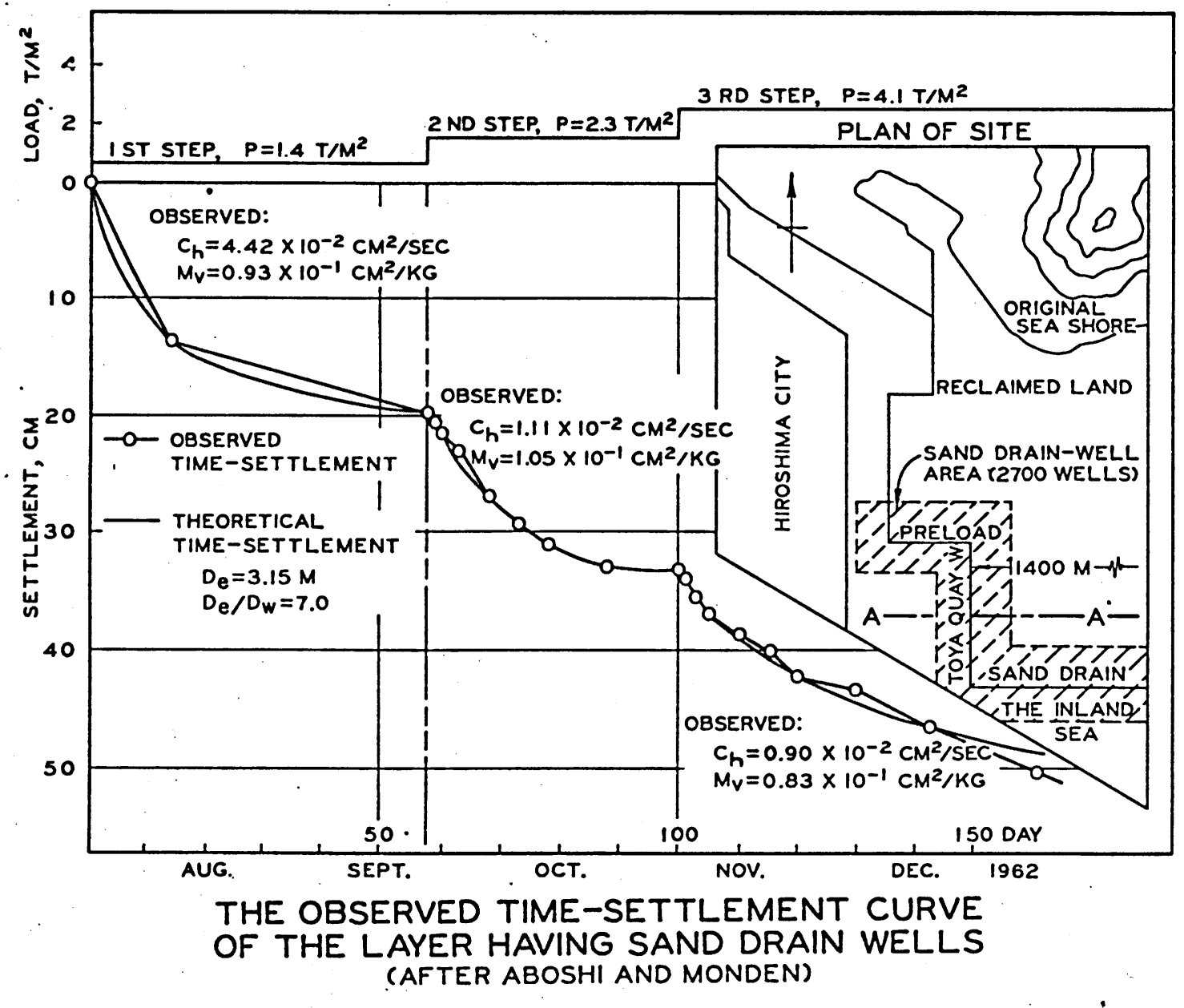


a central drain and also toward the exterior. These tests gave $c_{h} / c_{v}$ ratios of 2.7 for tests in a consolidometer and 1.7 for tests in a triaxial compression device. Field results (see Fig. 29) for the sand-drained portion checked closely the results from the consolidation tests with a central drain. 
FIELD CONSTRUCTION CONTROL

Failures that have occurred using the precompression technique with sand drains generally have resulted from insufficient construction control and evaluation of observations made during construction. It is essential that construction be regarded as an extension of the design phase in the sense that design assumptions are confirmed or found incorrect and revised to conform to actual field conditions as revealed by instrumentation provided for this purpose. While it is impossible to discuss this subject in detail. (see Reference 10), a few aspects may be of interest.

Preventing slides during construction is a prime objective that can generally be realized by: (1).. making adequate design stability analyses; (2) preventing local buildups of fill that overstress the subsoils; (3) using appropriate fillplacement techniques, including casting firl ahead if required; and (4) evaluating promptly and properly observations on settlement plates, piezometers, side stakes, and slope indicators, although the latter may be hard to interpret quantitatively. It is now realized that much more lateral deformation occurs than had been generally realized.

The rate and degree of consolidation are difficult or impossible to determine from settlement observations during construction but can be done easily from piezometer observations. The method developed by Gould 40 for determining the field coefficient of consolidation was for vertical consolidation and can readily be extended for radial flow to sand drains, ${ }^{10}$ as shown in Fig. 30. Combined vertical and radial flow can be handled in a trial-and-error solution process by assuming that $c_{v}=c_{h}$ or that $c_{v}$ is a constant. fraction of $c_{h}$ (see Reference 10).

Another means for simply determining approximate field $c_{h}$ values during construction is based upon the straight-line relationship between the excess. 


\section{FIELD COEFFICIENT OF CONSOLIDATION AT ANY TIME}

VERTICAL DRAINAGE: (PER GOULD)

$$
\begin{aligned}
& \sigma_{\mathrm{V}}=\Delta \mathrm{H}_{\mathrm{l}} \cdot{ }^{\cdot} \quad \text { AVERAGE CONSOLIDATION } \\
& \bar{J}_{v}=\frac{\Delta H_{t}}{\Delta H_{u l t}} ; \quad \text { FROM SETTLEMENT } \\
& U_{v}=1-\frac{u_{t}}{u_{0}} ; \quad \begin{array}{l}
\text { POINT CONSOLIDATION } \\
\text { FROM PIEZOMETERS }
\end{array} \\
& C_{v}=\frac{T_{v} H^{2}}{t} \quad \text { OR } \quad C_{v}=\frac{\Delta T_{v}}{\Delta t} H^{2} \\
& \text { OR } \quad C_{v}=\frac{T_{v 2}-T_{v 1}}{t_{2}-T_{1}} H^{2}
\end{aligned}
$$

$t_{2}$ AND $t_{1}$ ARE SETTLEMENT OR PIEZOMETER OBSERVATIONS AT TWO DIFFERENT TIMES; $T_{\mathrm{v} 2}$ AND $T_{\mathrm{v} !}$ ARE CORRESPONDING TIME FACTORS, FROM CONSOLIDATION THEORY.

\section{RADIAL DRAINAGE TO SAND DRAINS:}

$$
\begin{aligned}
& \overline{\mathrm{U}}_{\mathrm{R}}=\frac{\Delta \mathrm{H}_{\mathrm{t}}}{\Delta \mathrm{H}_{\mathrm{UIt}}} ; \quad \begin{array}{l}
\text { AVERAGE CONSOLIDATION } \\
\begin{array}{l}
\text { FROM SETTLEMENT } \\
\text { OBSERVATIONS }
\end{array}
\end{array} \\
& -U_{R}=1-\frac{U_{f}}{U_{0}} ; \quad \begin{array}{l}
\text { POINT CONSOLIDATION } \\
\text { FROM PIEZOMETERS }
\end{array} \\
& C_{v-R}=\frac{T_{h} d_{e}^{2}}{t} \quad \text { OR } \quad C_{v-R}=\frac{\Delta T_{h} d_{e}^{2}}{\Delta t} \\
& \text { OR } \quad C_{V-R}=\frac{T_{h 2}-T_{h 1}}{t_{2}-T_{1}} d_{e}
\end{aligned}
$$


pore-pressure ratio $\frac{\mathrm{u}}{\mathrm{u}_{0}}$ and the time factor $\mathrm{T}_{\mathrm{h}}$ (see Figs. 7,8 , and 31 ), as pointed out by Aboshi and Monden 39 and previously by Escario and Uriel. 41 If $\frac{t}{d_{e}^{2}}$ is substituted for $T_{h}$, Constant $c_{h}$ values result in straight lines for constant $n$ values, and plots of the type shown in Fig. 31 are useful for obtaining approximate average values of $c_{h}$ as consolidation proceeds. Master charts can be prepared for field use that simplify. plotting of data as they are obtained. Gould's procedure is simple and provides a sensitive measure of variations in $c_{h}$ during construction, and both methods are recommended.

The field coefficient of consolidation can also be simply evaluated from settlement observations during preloading using a procedure developed by scott 42 for laboratory consolidation tests, as pointed out be Adachi and Miyrahama. 43 The latter authors also describe a somewhat more involved procedure using field pore-water pressures, based on work by Mätsuo. 44

It is essential to obtain field values for $c_{h}$ as early as possible during construction to verify design assumptions and to permit changes to be made in surcharge thickness during construction, if necessary. Howevor, when predicting future field behavior on the basis of $c_{h}$ values computed during construction, the expected decrease of $c_{h}$ with consolidation should be accounted for. 


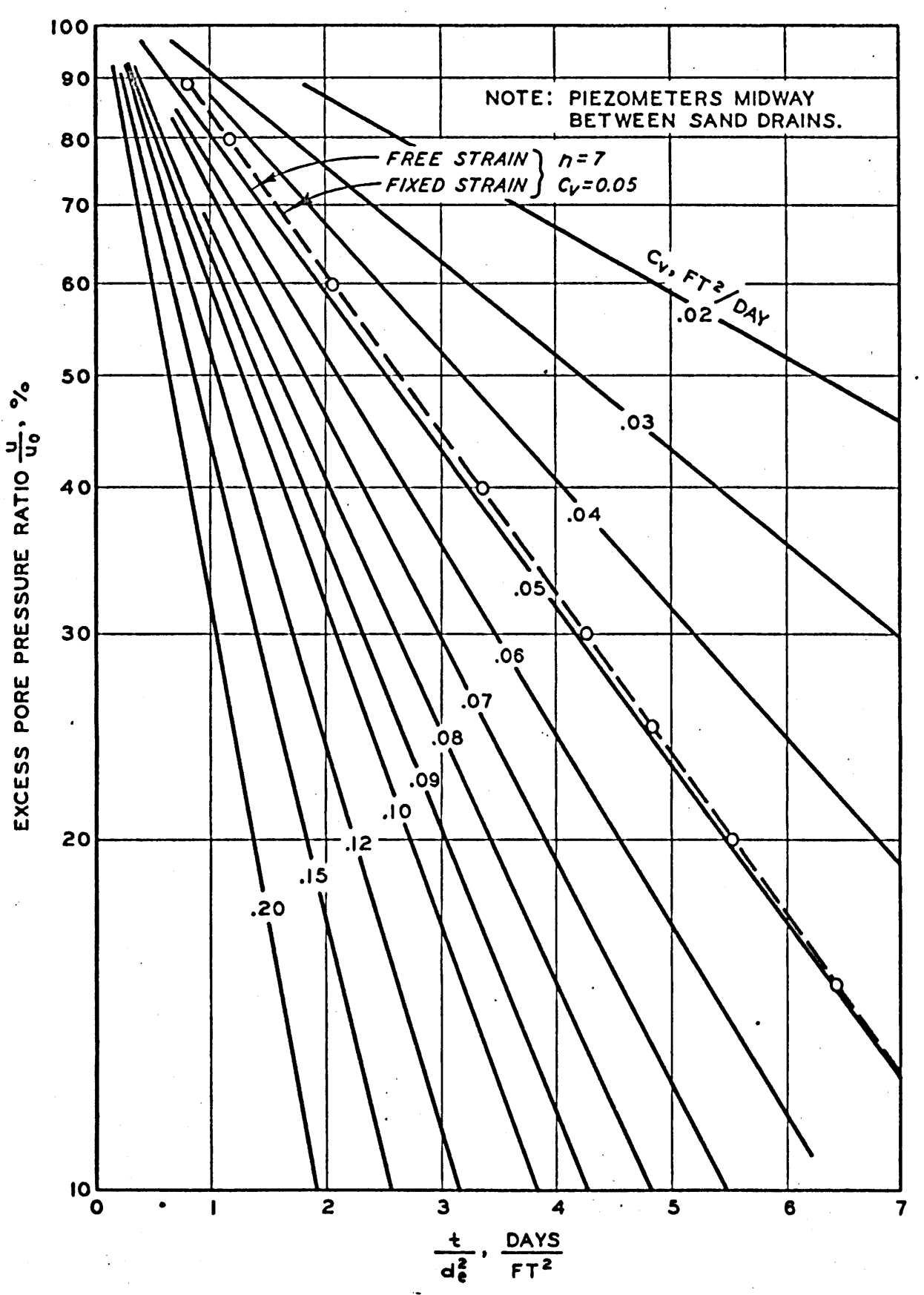

GRAPH FOR DETERMINING $C_{V}$ FROM PIEZOMETER OBSERVATIONS

$$
\frac{t}{d_{e}^{2}} v s \frac{u}{u_{0}}
$$


The precompression technique combined with vertical sand drains is definitely not a cure-all but is often applicable where structure loads are reasonably uniform and do not include heavy concentrated loadings and where earth fills for highways do not exceed 40 to $50 \mathrm{ft}$, although this limitation is variable. The method often saves very large sums and can be used where subsoil conditions are unusually poor. Where properly applied, the method can be used with confidence.

Precompression with vertical sand drains can eliminate postconstruction settlement that would result from primary consolidation and can reduce postconstruction secondary compression settlements to tolerable values. The results achieved can meet severe limitations on postconstruction settlements but are obtained at the expense of added cost or longer preloading periods.

Precompression with vertical sand drains is useful for stabilizing foundations beneath embankments, buildings, slopes, and a variety of related applications requiring increased foundation shear strengths or accelerated consolidation.

Precompression design with vertical sand drains requires thorough field explorations, laboratory testing, and design analyses. These are relatively time-consuming, highly demanding of technical skill, and frequently more costly than required for other construction alternatives. However, feasibility designs can generally be prepared from previous experiences, available soil property correlations, and relatively incomplete field boring data. The added cost of final design investigations is usually of minor importance compared to cost savings where the technique is applicable.

Precompression with vertical sand drains may require surcharge loading periods varying from a few months to a year or more. Those responsible for planning and scheduling work in areas of poor subsoils need to consider the time required, if potential cost savings are to be realized. 
Vertical sand drains to accelerate consolidation are probably not required where soils contain continuous intermediate sand layers within the compressible stratum, but pressure-relief wells may be required to reduce excess porewater pressures in the sand layers. The pressure-relief wells can be sand drains, free-flowing wellpoints, or conventional wells. Also, vertical sand drains will probably serve no purpose where design loadings will not exceed preconsolidation stresses. Field tests may be required in some stratified materials to evaluate the efficacy of thin pervious soils as drainage layers.

Vertical sand drains are often not required in peaty materials because of the high permeability of peaty materials under low-to-moderate loadings. They may be required, however, for underlying soft clays.

When considering use of precompression with vertical sand drains, it can be assumed that this technique, with displacement-type sand drains, will work at least as well as predicted using available design procedures, results of conventional consolidation tests without allowance for smear or disturbance, and conservative assumptions and analyses, unless design loadings are small, which is generally not the case. For final design, field permeability tests and/or laboratory consolidation tests on large samples in consolidometers simulating radial drainage are recommended but must be used with reference to increased effective strèsses after consolidation.

Increased economy may result from using nondisplacement-type sand drains, but field tests comparing the various types with each other and with displacement-type drains are required for a variety of soil conditions. None such installations have been reported, and only one such installation is known to be in progress. 
1. Johnson, S. J., "Precompression for Improving Foundation Soils," state-of-the-art talk, Session II, ASCE Specialty Conference on Placement and Improvement of Soil to Support Structures, Massachusetts Institute of Technology, Aug., 1968. (Submitted to ASCE for publication, spring, 1969.)

2. Porter, O. J., "Studies of Fill Construction Over Mud Flats Including a Description of Experimental Construction Using Vertical Sand Drains to Hasten Stabilization, Proceedings, Ist International Conference on Soil Mechanics and Foundation Engineering, Vol. I, 1936, pp. 229-235.

3. Barron, R. A., "The Influence of Drain Wells or the Consolidation of Fine-Grained Soils," U.'S. Army Engineer District, Providence, 1944. •

4. Terzaghi, K., "Shipways with Cellular Wall on a Marl Foundation," Transactions, ASCE, Vol. 112, 1947, p. 307.

5. Ackerman, A. J., and Jansen, C. B., "Submerged Shipways with Steel Sheeting Walls," Civil Engineering, July, 1943, p. 309.

6. Barron, R. A., "Consolidation of Fine-Grained Soils by Drain Wells," Transactions, ASCE, Vol. 113, 1948, pp. 718-754.

7. Rendulic, I., "Der Hydrodynamische Spannungsausgleich in Zentral Entwasserten Tanzylindern," Wasserwirtschaft und Technik, Vol. 2, 1935.

8. Carrillo, N., "Simple Two- and Three-Dimensional Cases in the Theory of Consolidation of Soils," Journal of Mathematics and Physics, Vol. 2l, No. I, March, 1942.

9. Rutledge; P. C., and Johnson, S. J., "Review of Uses of Vertical Sand Drains," Highway Research Board, Bulletin 173, 1957. 
10. Moran, Proctor, Mueser, and Rutledge, "Study of Deep Soil Stabilization by Vertical Sand Drains," report to Bureau of Yards and Docks, Department of the Navy, June, 1958. (Reprinted by Office of Technical Services, Department of Commerce.)

11. Richart, F. E., Jr., "A Review of the Theories for Sarid Drains," Transactions, ASCE, Vol. 124, 1959, p. 709.

12. Aldrich, H. P., "Precompression for Support of Shallow Foundations," Journal of Soil Mechanics and Foundations Division, ASCE, Vol. 91, No. SM2, March, 1965.

13. Landau, R. E., "Method of Installation as a Factor in Sand Drain

- Stabilization Design," Highway Research Record, No. 133, 1966.

14. Weber, W. G., Jr., "Experimental Sand Drain Fill at Napa River," Highway Research Record, No. 133, 1966.

15. Hansbo, S., "Consolidation of Clay, with Special Reference to Influence of Vertical Sand Drains," Proceedings, Swedish Geotechnical Institute, No. 18, 1960.

16. Schiffman, R. L., "Consolidation of Soil Under Time-Dependent Loading and Varying Permeability," Proceedings, Highway Research Board, Vol. 37, 1958, p. 584 .

17. Rowe, P. W., "The Calculation of the Consolidation Rates of Laminated, Varved or Layered Clays, with Particular Reference to Sand Drains," Geotechnique, England, Vol. XIV, No. 4, Dec., 1964, p. 321. ..

18. Horne, M. R., "The Consolidation of a Stratified Soil with Vertical and Horizontal Drainage," International J. Mechanical Sciences, Vol. 6, 1964, p. 187.

19. Younger, J. S., "Design Procedure for Sand Drains," Civil Engineering and Public Works Review, England, March, 1968, pp. 285-291. 
20. Rowe, P..W., and Barden, I., "A New Consolidation Cell, " Geotechnique, England, Vol. XVI, No. 2, June, 1966, p. 162.

21. Rowe, P. W., and Shields, D. H., "The Measured Horizontal Coefficient of Consolidation of Laminated, Layered or Varved Clays," Proceedings, 6th International Conference on Soil Mechanics and Foundation Engineering, Vol. I, 1965, p. 342 .

22. Shields, D. H., and Rowe, P. W., "Radial Drainage Oedometer for Laminated Clays," Journal of the Soil Mechanics and Foundations Division, ASCE, Vol. 91, No. SMl, Jan., 1965, p. 15.

23. Aboshi, H., and Monden, H., "Determination of the Horizontal Coefficient of Consolidation of an Alluvial Clay," Proceedings, 4th Australia - New Zealand Conference on Soil Mechanics and Foundation Engineering, 1963, pp. 159-164.

24. Kulkarni, K. R., et al., "A Study of the Properties of Bombay Marine Clay Deposits in Relation to Certain Foundation Problems, "Proceedings, 3rd Asian Regional Conference on Soil Mechanics and Foundation Engineering, Vol. I, 1967, pp. 210-214.

25. Cedergren, H. R., and Weber, W. G., Jr., "Subsidence of California Highways," ASTM Special Technical Publication No. 322, 1962.

26. Hvorslev, M. J., "Time Iag and Soil Permeability in Ground-Water Observations," Bulletin No. 36, U. S. Army Engineer Waterways Experiment Station, CE, Vicksburg, Miss., 1951.

27. Weber, W. G., Jr., "In Situ Permeabilities for Determining Rates of Consolidation," Highway Research Record, No. 243, 1968.

28. Rowe, P. W., "The Influence of Geological Features of Clay Deposits on the Design and Performance of Sand Drains," Proceedings, The Institution of Civil Engineers, Paper 7058-S, Supplementary Volume, 1968. (See March 1968 issue, Vol. 39, p. 465, for summary.) 
29. "Jetting. Procedure for Vertical Sand Drains," Civil Engineering and Public Works Review, England, Feb., 1965, p. 217.

30. Simons, N. E., Discussion, Proceedings, Conference on Design of Foundations for Control of Settlement, Soil Mechanics and Foundations Division, ASCE, 1964.

31. Simons, N. E., "Consolidation Investigation on Undisturbed Fornebu Clay;" Norwegian Geotechnical Institute, Oslo, Publication No. 62, 1965.

32. Orrje, 0., and Broms, B., "Effects of Pile Driving on Soil Properties," Journal of the Soil Mechanics and Foundations Division, ASCE, Vol. 93,

No. SM5, Part 1, Sept., 1967, p. 59 ff.

33. Simons, N. E., Discussion, Proceedings, Conference on Pore Pressure and Suction in Soils, Institution of Civil Engineers, London, Butterworths, Mar., 1960, p. 125.

34. Schmidt, T. J., and Gould, J. P., "Consolidation Properties of an Organic Clay Determined from Field Observations," Highway Research Record, No. $243,1968$.

35. Aldrich, H. P., Remarks made as panel member, Session III, ASCE Specialty Conference on Placement and Improvement of Soils to Support Structures, .. Massachusetts Institute of Technology, Aug., 1968.

36. Boutsma, K., and Horvat, E., "The Advantages and Disadvantages of the Application of Sand Drains and Preloading at an Excavation in Rotterdam," Proceedings, Geotechnical Conference on Shear Strength Properties of Natural Soils and Rocks, Norwegian Geotechnical Institute, July, 1967. 37. Moore, L. H., "Summary of Treatments for Highway Embankments on Soft Foundations," Highway Research Record, No. 133, 1966.

38. Parsons, J. D., "Stabilization and Preparation of Marginal Areas for Building Construction," talk presented before Metropolitan Section, ASCE, New York, N. Y., 26 Mar., 1968. 
39. Aboshi, H., and Monden, H., "Determination of the Horizontal Coefficient of Consolidation of an Alluvial Clay," 4th Australia - New Zealand Conference on Soil Mechanics and Foundation Engineering, 1963, p. 159.

40. Gould, J. P., "Analysis of Pore Pressure and Settlement Observations at Logan International Airport," Harvard Soil Mechanics Series No. 34, Harvard University, Dec., 1949.

41. Escario, V., and Uriel, S., "Determining the Coefficient of Consolidation and Horizontal Permeability by Radial Drainage," Proceedings, 5th International Conference on Soil Mechanics and Foundation Engineering, Vol. 1, 1961, p. 83.

42. Scott, R. F., "New Method of Consolidation - Coefficient Evaluation," Journal, Soil Mechanics and Foundation Division, ASCE, Vol. 87, No. SM, Feb., 1961. (Also, see closing discussion, Vol. 88, No. SMI, Feb., 1962.)

43. Adachi, K., and Miyrahama, K., "Test Fill on Soft Ground," Soil and Foundation, Japanese Society of Soil Mechanics and Foundation Engineering, Vol. III, No. 2, Mar., 1963, pp. 63-80.

44. Matsuo, H., "Consolidation of Soft Foundation Ground and Treatment," Chugoku - Shikoku Branch, Japanese Society of Civil Engineering, Aưg., $\therefore 1953$.

45. Anakakrishnan, M., "A Study of Some of the Variables of Consolidation Theory as Applied to Vertical Sand Drain Design," PhD Dissertation, University of Minnesota, 1960. 
The following symbols are used in this paper:

$a_{v}=$ coefficient of compressibility;

$a_{v-v}=$ coefficient of compressibility for vertical consolidation;

$\mathbf{C}_{\mathrm{C}}=$ compression index;

$C_{V-R}=$ Coefficient of consolidation for radial drainage and vertical consolidation;

$c_{h}, c_{v-h}=$ coefficient of consolidation for horizontal drainage and vertical consolidation;

$c_{\mathrm{v}}=$ coefficient $\cdot$ of consolidation;

$c_{v-v}=$ coefficient of consolidation for vertical drainage and vertical consolidation;

$\Delta c=$ increase in shear resistance;

$d_{e}=$ effective diameter of area tributary to a sand drain;

$\mathrm{d}_{\mathrm{w}}=$ effective diameter of sand drain;

e = void ratio;

$e_{0}=$ initial void ratio;

$\mathrm{H}=$ layer thickness for one-way drainage;

$\Delta \mathrm{H}_{t}=$ settlement at time $t$;

$\Delta \mathrm{H}_{\mathrm{ult}}=$ settlement at completion of primary consolidation;

$k_{h}=$ coefficient of permeability for horizontal flow;

$\mathrm{k}_{\mathrm{v}}=$ coefficient of permeability for vertical flow;

$\mathrm{n}=$ ratio of drain spacing to drain diameter, $\mathrm{n}=\frac{\mathrm{d}_{\mathrm{e}}}{\mathrm{d}_{\mathrm{w}}}$;

$\stackrel{\mathrm{P}}{\mathrm{c}}_{\mathrm{f}}=$ preconsolidation stress;

$\Delta p=$ increase in effective stress;

$r=$ radius; 
$r_{e}=$ effective radius of area tributary to a sand drain;

$r_{W}=$ effective radius of sand drain;

$S=$ drain spacing;

$T_{h}, T_{h l}, T_{h 2}=$ time factors for radial drainage and vertical consolidation;

$\mathrm{T}_{\mathrm{v}}, \mathrm{T}_{\mathrm{vl}}, \mathrm{T}_{\mathrm{v} 2}=$ time factors for vertical drainage and vertical consolidation;

$\Delta \mathrm{T}_{\mathrm{v}}=$ change in time factors;

$t, t_{1}, t_{2}=$ time;

$\mathrm{U}=$ percent consolidation at any point;

$\overline{\mathrm{U}}=$ average percent consolidation;

$\dot{\bar{U}}_{\mathrm{R}}=$ average percent consolidation for radial drainage only and vertical consolidation;

$\mathrm{U}_{\mathrm{V}}=$ percent consolidation at any point for vertical drainage and vertical consolidation;

$\overline{\mathrm{U}}_{\mathrm{V}}=$ average percent consolidation for vertical drainage and vertical consolidation;

$u=$ excess pore-water pressure at a point;

$\bar{u}=$ average excess pore-water pressure;

$u_{0}=$ initial excess pore-water pressure;

$\vec{u}_{v}=$ average excess pore-water pressure for vertical drainage only;

$\left(\frac{\bar{u}}{u_{0}}\right)_{h}=$ excess pore-water pressure ratio for horizontal drainage only;

$\left(\frac{\bar{u}}{u_{0}}\right)_{h}=$ average excess pore-water pressure ratio for horizontal drainage only;

$\left(\frac{u}{u_{0}}\right)_{v}=$ excess pore-water pressure ratio for vertical drainage only;

$\left(\frac{\bar{u}}{u_{0}}\right)_{v}=$ average excess pore-water pressure ratio for vertical drainage only; 
$\left(\frac{u}{u_{0}}\right)_{v+h}=$ excess pore-water pressure ratio for combined vertical and horizontal drainage;

$\left(\frac{\bar{u}_{\mathrm{u}}}{\mathrm{u}_{0}}\right)_{\mathrm{v}+\mathrm{h}}=$ average excess pore-water pressure ratio for combined vertical and $\mathrm{v}+\mathrm{h}$ horizontal drainage;

$\mathrm{w}=$ water content;

$\mathrm{Z}=$ depth;

$\gamma_{W}=$ unit weight of water; 
Typical Sand Drain Installation

2

Cost of Structure Versus Earth Fill for Highway Construction

(After Iandau)

Flow to Vertical Sand Drains

4

(No title, tabulation)

Consolidation by Vertical Drainage. Hydrostatic Excess Pressure as

a function of Time Factor $\mathrm{T}_{\mathrm{v}}$ and Position $\mathrm{Z} / \mathrm{H}$, and Average for Entire Layer $\frac{\bar{u}_{v}}{u_{0}}$

6. Nomograph for Consolidation with Radial Drainage to Vertical Sand Drains. Equal Strain Condition

Consolidation by Radial Drainage. Average Hydrostatic Excess Pressure as Function of Time Factor $T_{h}$ for Varying Drain Spacing $n$ Consolidation by Radial Drainage, Hydrostatic Excess Pressure as Function of Time Factor $\mathrm{T}_{\mathrm{h}}$ and Drain Spacing $\mathrm{n}$ at Outer Boundary, $r=1.0 r_{e}$

Excess Pore-Water Pressure Versus Radial Distance from Sand Drain. Radial Flow Only, $n=\frac{r_{-e}}{r_{w}}=10$

Hollow-Stem Auger for Instaliing Sand Drains (After Landau)

11 Consolidation Test with Central Sand Drain (After Hansbo) Effect of Disturbance and Variation of $c_{v}$ with Effective Stress (After Hansbo)

Settlements with Surcharge Fill with Sand Drains. Time-Rate Plot for Fill Construction and Settlement, Oswego Boulevard, Syracuse, N. Y. (After Moore) 
Pore-Pressure Dissipation Surcharge Fill with Sand Drains. TimeRate Plot for Fill Construction and Pore Pressures, Oswego Boulevard, Syracuse, N. Y. (After Moore)

15 Settlements and Moisture Content Decrease Surcharge Fill with Sand Drains, Oswego Boulevard, Syracuse, N. Y. (After Moore) Comparison of Field and Laboratory Determined Values for e, $\mathrm{C}_{\mathrm{c}}$, and $c_{V}$, Piezometers PI3 and PI3A (After Schmidt and Gould) Comparison of Field and Laboratory Determined Values for $c, c_{c}$; and $c_{\mathrm{v}}$, Piezometers P2 and P2A (After Schmidt and Gould) (No title, tabulation) (No title, tabulation) Plan of Test Areas at Sk̊̊-Edeby (After Hansbo) Effect of Sand Drain Spacing Test Area I (After Hansbo) Effect of Fill Thickness in Areas with and without Sand Drains Test Areas II to IV (After Hansbo) (No title, photograph) (No title, photograph)

Sargent Building Area Settlement Prior to Surcharge Removal April 1, 1963 (After Parsons)

Settlement Sargent Building (After Parsons)

Sargent Manufacturing Building Settlements since Construction in July 1964 to September 1967 (After Parsons)

A Section Showing Sand Drain Wells and Subsoil Conditions (After Aboshi and Monden) Wells (After Aboshi and Monden) (No title, tabulation) 